\title{
Theoretical Study Oxygen Reduction Activity of Phosphorus-doped Graphene Nanoribbons
}

\author{
Zeming Xie ${ }^{1}$, Chao Liu ${ }^{1,2,}$, Mingming Luo ${ }^{1}$, Zhao Liang ${ }^{1}$, Shaik Gouse Peera ${ }^{3}$ and \\ Tongxiang Liang ${ }^{1, *}$
}

${ }^{1}$ Faculty of Materials Metallurgy and Chemistry, Jiangxi University of Science and Technology, Ganzhou 341000, China; '2 State Key Laboratory of Metastable Materials Science and Technology, Yanshan University, Qinhuangdao 066004, China and ${ }^{3}$ Department of Environmental Science and Engineering, Keimyung University, Daegu 42601, Republic of South Korea

\begin{abstract}
Phosphorus-doped graphene is known to exhibit good electrocatalytic activity for oxygen reduction reaction (ORR). While the ORR activity of P-doped graphene nanoribbons (PGNR) is still unclear. Taking the common graphene nanoribbons with the edges of armchair as an example in this study, we research the mechanistic investigation of ORR on the PGNR under acidic electrolytic conditions by density functional theory (DFT). Based on the keen observation of the atomic charge distribution and adsorption energy at different sites, $\mathrm{P}$ atom in PGNR is considered to be the strongest adsorption site with oxygen. Detailed ORR mechanistic was deduced by the investigation of reaction heat, reaction barrier for each possible step and molecular dynamics (MD) simulation. Based on our calculations, when the contribution of the intermediate product to the ORR activity is not considered, PGNR does not possess the property as an ORR catalyst due to several high reaction barriers and some endothermic reactions for ORR path.
\end{abstract}

Keywords: Metal-free catalysis, Phosphorus doped graphene nanoribbons, Density functional theory, Oxygen reduction reaction.

\section{INTRODUCTION}

At present, the major source of energy is produced from burning of fossil fuels [1]. The non-renewability of fossil fuel energy and the growing environmental problems caused by gaseous products produced from burning of fossil fuels, which have motivated researchers to develop sustainable and clean energy production technologies in order to meet growing energy demand and environmental protection, have drawn a considerable attention last few decades. Despite numerous energy sources, hydrogen energy has attracted much attention because of its carbon-free emission characteristics and the calorific value of $34000 \mathrm{Kcal} / \mathrm{kg}$ (three times that of gasoline). With a rapid development in hydrogen production and hydrogen storage technology, the role of hydrogen fuel cells is gaining foremost importance. Functionally, hydrogen fuel cells, which converts hydrogen energy directly into electrical energy, hold the advantages of high energy density, high efficiency and negligible amounts of harmful gas emissions. As the critical process in entire discharge stage of the fuel cell, the electrochemical oxygen reduction reaction (ORR) has received extensive attention due to the complicated mechanism. Compared to the anodic oxidation

*Address correspondence to this author at the Faculty of Materials Metallurgy and Chemistry, Jiangxi University of Science and Technology, Ganzhou 341000, China; E-mail: liuchao198967@126.com and liang_tx@126.com reaction, the cathodic ORR exhibits more sluggish rate, hence the ORR is the key limiting factor in the energy conversion efficiency of fuel cells [2, 3]. By consuming the electrons from the anode, the cathodic ORR almost determines the discharge voltage of the whole fuel cell. It's highly necessary to catalysts ORR due to the sluggish kinetics. Therefore, development of an efficient and stable ORR catalyst has stirred up researcher's interest. Currently, Pt-based catalytic system is the most widely used efficient catalyst [4, 5]. However, limited reserves, high cost and agglomeration of Pt nanoparticles under fuel cell conditions, limits the commercial application of $\mathrm{Pt} / \mathrm{C}$ catalyst $[4,5]$. Therefore, it is highly desirable to develop low-cost and durable catalyst to take the place of traditional $\mathrm{Pt} / \mathrm{C}$ catalyst.

Among various types of catalytic materials, heteroatom (C, N, S, B and P) doped carbon nanostructured catalytic materials are considered as promising metalfree catalysts for replacing Pt-based catalytic materials [6-8]. It is well known that the different spin and charge densities of the carbons surrounded heteroatoms, attributes to abundant ORR active sites [9-12]. Moreover, these carbon nanomaterials are not only rich in source, but also have good stability (including acid and alkali resistance, high temperature resistance, oxidation resistance, carbon monoxide resistance, etc.) [13-15]. Thus, various doped carbon materials have been synthesized and assessed for ORR activity [1622]. Of course, theoretical investigations are also a 
very important part to develop efficient catalysts [23], but they are still lacking in this aspect.

Common types of doped carbon materials include graphene, carbon nanotubes, graphene nanoribbons, carbon nanosheets, etc., all of which contain a $\pi-$ conjugated system [6, 24-27]. Compared to other types of carbon nanomaterials, graphene nanoribbons have some special properties. First, Graphene nanoribbons have a band gap [28], and a suitable band gap facilitates catalytic activity [29]. Secondly, the open structure on both sides of graphene nanoribbons can increase the possibility of $\mathrm{O}_{2}$ adsorption [30]. Then, graphene nanoribbons possess unique edge structure (including zigzag edges and armchair edges), which allows those doping elements to have different ORR activities. At last, flexible nature of graphene nanoribbons prevent agglomeration and exfoliation [31, 32].

$\mathrm{N}$ doped carbons were mostly investigated as metal-free catalysts, and the high electronegativity of $\mathrm{N}$ makes $\mathrm{N}$ dopants to induce bond polarity. However, other heteroatom from the nitrogen group element, phosphorus with a lower electronegativity than $\mathrm{N}$, induces the opposite bond polarity. Moreover, the P-C bond has a longer bond length than the $\mathrm{C}-\mathrm{C}$ bond. This difference in bond lengths induces a strain and forces the $\mathrm{P}$ dopant to protrude from basal hexagonal carbon network, thereby promoting reduction of $\mathrm{O}_{2}$ on the $\mathrm{P}$ atom. However, the detailed ORR mechanism on PGNR has not been clearly investigated. In this study, ORR on a PGNR was systematically investigated and possible reaction pathways for oxygen reduction were proposed.

\section{COMPUTATIONAL DETAIL}

\subsection{Computational Model}

An armchair PGNR doping a $\mathrm{P}$ atom was considered in this study. Hydrogen atoms cover all of the $\sigma$ dangling bonds on the edges of nanoribbons. Supercells of P1 symmetry were constructed with lattice dimensions were set as $12.7825(\mathrm{x}) \times 30(\mathrm{y}) \times 20(\mathrm{z})$ $\AA^{3}$. PGNR grows along $x$ direction, and vacuum regions along $\mathrm{y}$ and $\mathrm{z}$ directions were intended to avoid interactions between PGNRs in adjacent cells.

\subsection{Computational Parameters}

All calculations were performed in the $\mathrm{Dmol}^{3}$ program $[33,34]$ based on DFT. The generalized gradient approximation with PBE (Perdew, Burke and Enzerhof) functional [35] was chosen as exchange- correlation functional. In order to describe the van-derWaals interactions, the empirical dispersion-correction proposed by Grimme [36] was chosen. The spin nonrestricted algorithm was employed. The conductor-like screening model were used to simulate aqueous solvent environment for all calculations and dielectric constant was set as 78.54 [37, 38]. The core treatment parameter used in all calculations was selected as all electron. A double numerical plus polarization [33] was used as the basis with the orbital cutoff radius value as $4.2 \AA$. A smearing value of $0.005 \mathrm{Ha}$ was used for geometry optimization and transition state search calculations. The convergence tolerance of energy, force and displacement were set as $10^{-5} \mathrm{Ha}, 0.001$ $\mathrm{Ha} / \AA$, and $0.005 \AA$, respectively. Charge transfer was analyzed by assigning Mulliken charges on optimized structures [39]. The Monkhorst-Pack k-point grid used in all calculations was $5 \times 1 \times 1$. Transition state search was performed by the linear/quadratic synchronous transit [40]. Taking into account the appropriate operating temperature of the proton exchange membrane module [41], molecular dynamics (MD) simulation at a temperature of $60^{\circ} \mathrm{C}$ in the NVT ensemble has been carried out for 1 ps with the time step of $1 \mathrm{fs}$.

\subsection{Energy Calculation}

The adsorption energy of adsorbed molecules on PGNR is defined by the formula: $E_{a d}=E_{m o l}+P G N R-E_{m o l}$ - EPGNR. Where $E_{P G N R}, E_{m o l}$, and $E_{m o l+P G N R}$ were the total energy of substrate, ORR intermediates and the most stable adsorption configuration, respectively. For hydrogen fuel cells with proton exchange membranes, this model was assumed to be in an environment with $\mathrm{pH}=0$. In addition, the transition state was searched under the LH mechanism [42]. Thermodynamic calculations was based on the computational hydrogen electrode (CHE) model proposed by Nørskov et al. [43, 44]. The overall free energy change $(\Delta G)$ is given as $\Delta \mathrm{G}=\Delta \mathrm{E}+\Delta \mathrm{ZPE}-\mathrm{T} \Delta \mathrm{S}+\Delta \mathrm{G}_{\mathrm{U}}+\Delta \mathrm{G}_{\mathrm{pH}}$, ZPE is zero-point energy and $S$ is entropy. Vibrational frequencies were calculated to determine ZPE and entropy contributions. The effect of electrode potential $\Delta G_{u}$ is denoted as $-e U$, where $U$ is applied electrode potential and $e$ is the elementary positive charge. $\Delta \mathrm{G}_{\mathrm{pH}}$ is the contribution of solvation environment, which is equal to $-\mathrm{kT} \ln 10 \times \mathrm{pH}$, where $\mathrm{k}$ is the Boltzmann constant and $\mathrm{T}$ is chose as $298.15 \mathrm{~K}$. As $\mathrm{pH}$ is 0 , the $\Delta \mathrm{G}_{\mathrm{pH}}$ is $0 \mathrm{eV}$ in all calculations [44]. To avoid direct calculation inaccuracy of $\mathrm{O}_{2}$ in the triplet state, the free energy of $\mathrm{O}_{2}$ was obtained from the equation: $\mathrm{G}_{\mathrm{O}_{2}}(\mathrm{~g})=\mathrm{G}_{\mathrm{H}_{2} \mathrm{O}}(\mathrm{l})-\mathrm{G}_{\mathrm{H}_{2}}(\mathrm{~g})+4.92 \mathrm{eV}$. The free energy of $\mathrm{H}_{2} \mathrm{O}$ in solution could be obtained in gas 
phase at a pressure of 0.035 bar, which was the equilibrium vapor pressure of $\mathrm{H}_{2} \mathrm{O}$ at $298.15 \mathrm{~K}$.

\section{RESULTS AND DISCUSSION}

\subsection{The PGNR Structure}

All stable configurations of PGNR were obtained by optimization based on DFT. $P$ atom was convex from the surface of graphene nanoribbon about $1.51 \AA$. In addition, the nanoribbon also warped (Figure 1a). At the same time, electrons at the Fermi level have a positive spin density value (Figure 1b), indicating that this model is magnetic. These results are consistent with the previous calculations [45-48].

In addition, the carbon atoms in graphene with high spin density or positive atomic charge density were electrocatalytically active catalytic sites [29]. First, charge density distribution on PGNR was calculated to determine possible active sites. Charge distribution on PGNR is non-uniform because $P(2.19)$ is less electronegative relative to $C(2.55)$, which results in a positive charge value (0.64) on the $P$ atom (Figure 1c). All carbon atoms adjacent to the doped $\mathrm{P}$ atoms possess a negative charge value of about -0.34 . The positively charged $\mathrm{P}$ atom facilitates the capture of $\mathrm{O}_{2}$ molecule. In addition, the charge density distribution of the $C$ atoms at edges also changes greatly. However, these carbon atoms have negative charge values.

Figure 1d shows the distribution of electron spin density on PGNR. P atoms, ortho and para carbon atoms with changes significantly of spin density distribution have potential to act as active sites. Moreover, according to our calculation results, this spin density distribution can only exist under the condition of fixed orbital occupations during the self-consistent field.

\subsection{The Oxygen Adsorption Reaction on PGNR}

Generally, the mechanism of the ORR process in acidic conditions is considered by two main pathways [49]: one is the four-electron pathway, and the ORR process can be divided into five reactions, which include an oxygen adsorption reaction and four hydrogenation reactions. Eventually the oxygen is reduced to two water molecules. The other is a twoelectron pathway, and the ORR process can be divided into three reactions, which include an oxygen adsorption reaction and two hydrogenation reactions. Eventually the oxygen is reduced to hydrogen peroxide. In the following discussion, four-electronic pathway are mainly considered. For the two-electron pathway, it can be rejected in the final MD analysis.

The oxygen adsorption reaction is the initial step of the ORR process, and the stability of the oxygen after adsorption will affect the type of subsequent reaction. Therefore, the configuration of oxygen adsorption was first studied. Our calculations show that only one type configuration can exist steadily. Because the adsorption capacity of $\mathrm{P}$ atom is much stronger than that of other atoms, and $\mathrm{P}$ atoms can be combined with two oxygen atoms at the same time, which reduces the possibility of oxygen bonding with other atoms.

This type configuration includes two similar configurations (Figure $\mathbf{2 a}$ and $\mathbf{2} \mathbf{b}$ ), and the orientations of the adsorbate are different. In these configurations, $\mathrm{O}_{2}$ was preferably adsorbed on PGNR by bonding to the $P$ atom to form a triangular ring (Eads $=1.39 \mathrm{eV})$. The P-O bond lengths were about $1.79 \AA$ and $1.64 \AA$, respectively. For further understanding, a PDOS analysis of the $\mathrm{P}$ atom and two $\mathrm{O}$ atoms was given (Figure $\mathbf{2 c}$ and $\mathbf{2 d}$ ). There is a strong overlap in the

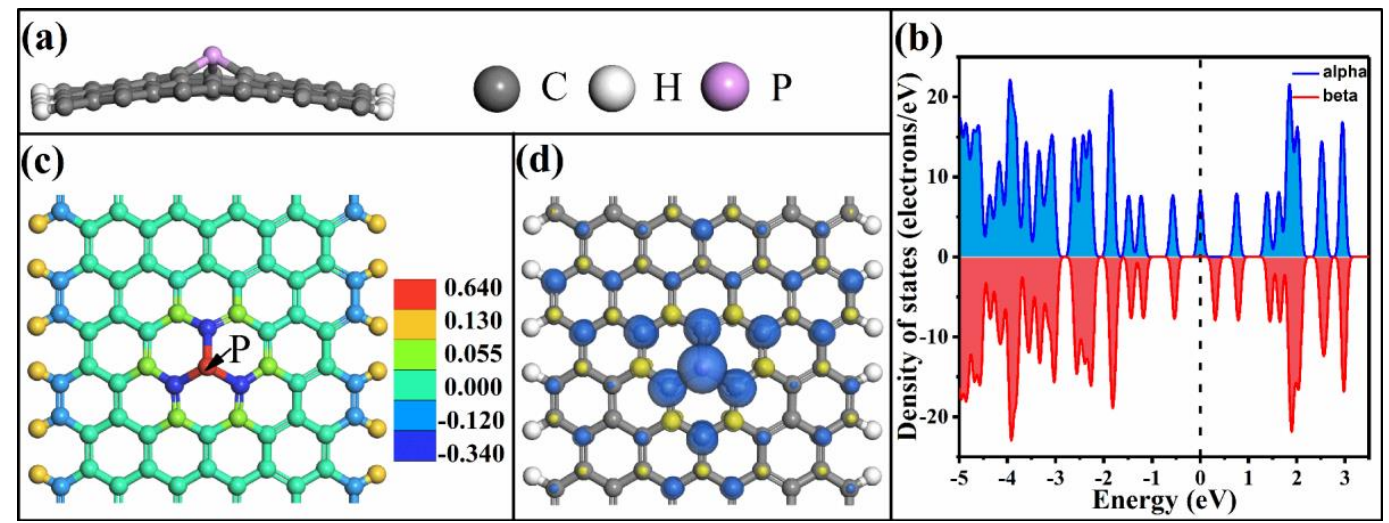

Figure 1: (a) Structure of PGNR and (b) computed density of states. (c) Mulliken charges of PGNR. The most positive value is red while the most negative value is blue. (d) The spin electronic density of the PGNR. Blue and yellow iso-surfaces correspond to positive and negative spin densities, respectively. The iso-surfaces level is $0.01 \mathrm{e} / \AA^{3}$. 


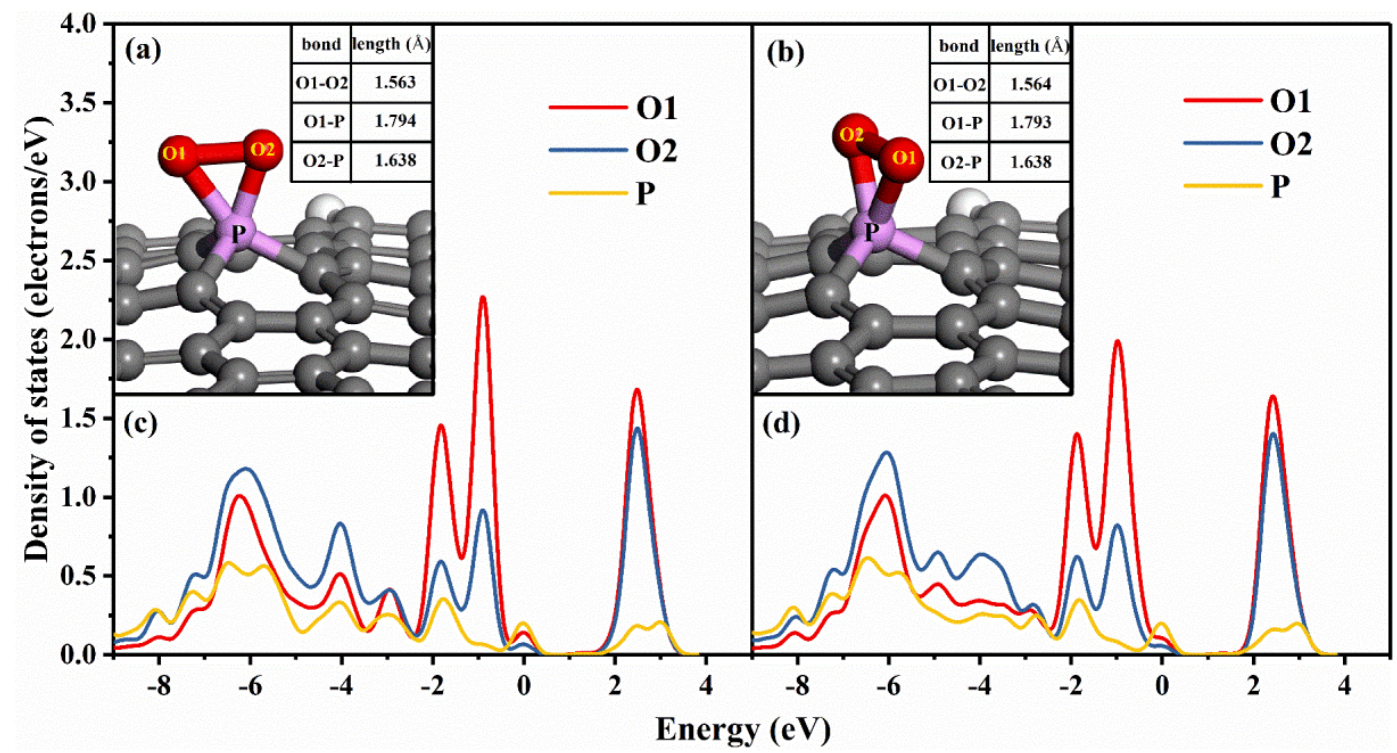

Figure 2: Local configuration of PGNR after oxygen adsorption (a, b) and partial density of states (PDOS) (c, d).

density of states, which shows a strong interaction between any two of the three atoms and reinforces the above argument.

Moreover, the hydrogenation reactions of these two configurations are quite similar. However, the reaction pathway remains independent most of the time due to the different orientations of the adsorbates. In the subsequent discussion, the ORR pathway of the configuration in Figure 1a is primarily considered. The other is shown in the support information (Figure S11 S17).

\subsection{ORR Pathways on PGNR}

The transition state search is based on the $\mathrm{LH}$ mechanism. Moreover, the reactants have been introduced with hydrogen atoms during the transition state search [50-52]. After the oxygen adsorption reaction, subsequent reactions are thought to follow one of two possible mechanisms: the dissociation mechanism that forms two separate oxygen atoms or the association mechanism that forms the ${ }^{*} \mathrm{OOH}$ configuration [49]. Here, ${ }^{*}$ denotes a site on the surface.

\section{A. The Dissociation Mechanism}

First, the reactions of dissociation mechanism were discussed. After the $\mathrm{O}-\mathrm{O}$ bond breaks, the chem.isorbed $\mathrm{O}_{2}$ turn into two separate $\mathrm{O}$ atoms (Figure 3 ). In the steady state, two $O$ atoms are each located at the top of $\mathrm{P}$ atom and at the bridging position of $\mathrm{P}-\mathrm{C}$ bond. This reaction had a relatively low reaction barrier $(0.204 \mathrm{eV})$ and was exothermic.
For the configuration of adsorbed oxygen and the configuration of dissociated oxygen, chemical stability can be analyzed from their charge deformation density. For the configuration of adsorbed oxygen (Figure 4a), electron aggregation shape around the $\mathrm{O}$ atom appears to be annular. The charge accumulation between the $O$ atom and the $P$ atom does not seem obvious. Of course, the ring aggregation has a certain degree of distortion, indicating that bonds are formed between the $\mathrm{O}$ atom and $\mathrm{P}$ atom. Moreover, this cyclic aggregation is very similar to the charge deformation density of hydrogen peroxide (Figure S1). Therefore, it is speculated that the oxygen atoms in the configuration of adsorbed oxygen and hydrogen peroxide may have similar chemical properties. For the configuration of dissociated oxygen (Figure $\mathbf{4 b}$ ), there is a very significant charge accumulation between the $\mathrm{O}$ atom and $\mathrm{P}$ atom, the $\mathrm{O}$ atom and $\mathrm{C}$ atom, indicating that a more stable chemical bond is formed between these atoms.

The system formed a ${ }^{*} \mathrm{OH}$ configuration after the first hydrogenation reaction. There might be two product configurations possible. One is obtained by adding a hydrogen atom to the oxygen atom above the $\mathrm{P}$ atom (Figure S2) and reaction barrier is $1.264 \mathrm{eV}$. The other is obtained by adding a hydrogen atom to the oxygen atom at the bridging position of $\mathrm{P}-\mathrm{C}$ bond (Figure S3) and reaction barrier is $2.708 \mathrm{eV}$. Due to high barrier energy, these reactions are unlikely.

The next hydrogenation reaction might form the first water molecule or produce another $\mathrm{OH}$ group. The 


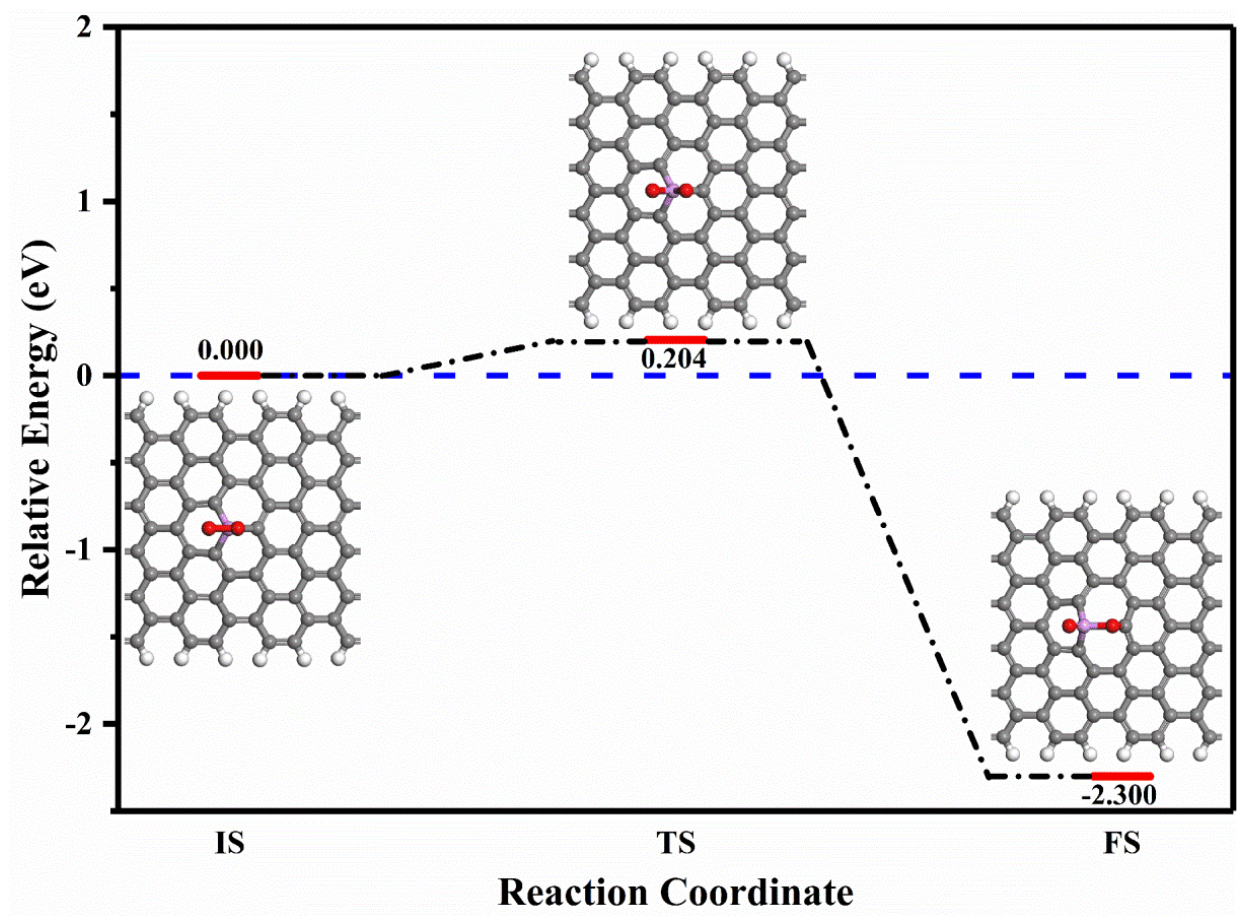

Figure 3: Structures of the initial state (left panel), transition state (middle panel), and final state (right panel) for the reaction: ${ }^{*} \mathrm{O}_{2} \rightarrow{ }^{*}\left(\mathrm{O}+{ }^{*} \mathrm{O}\right)$. The figure also includes the reaction heat and reaction barrier.

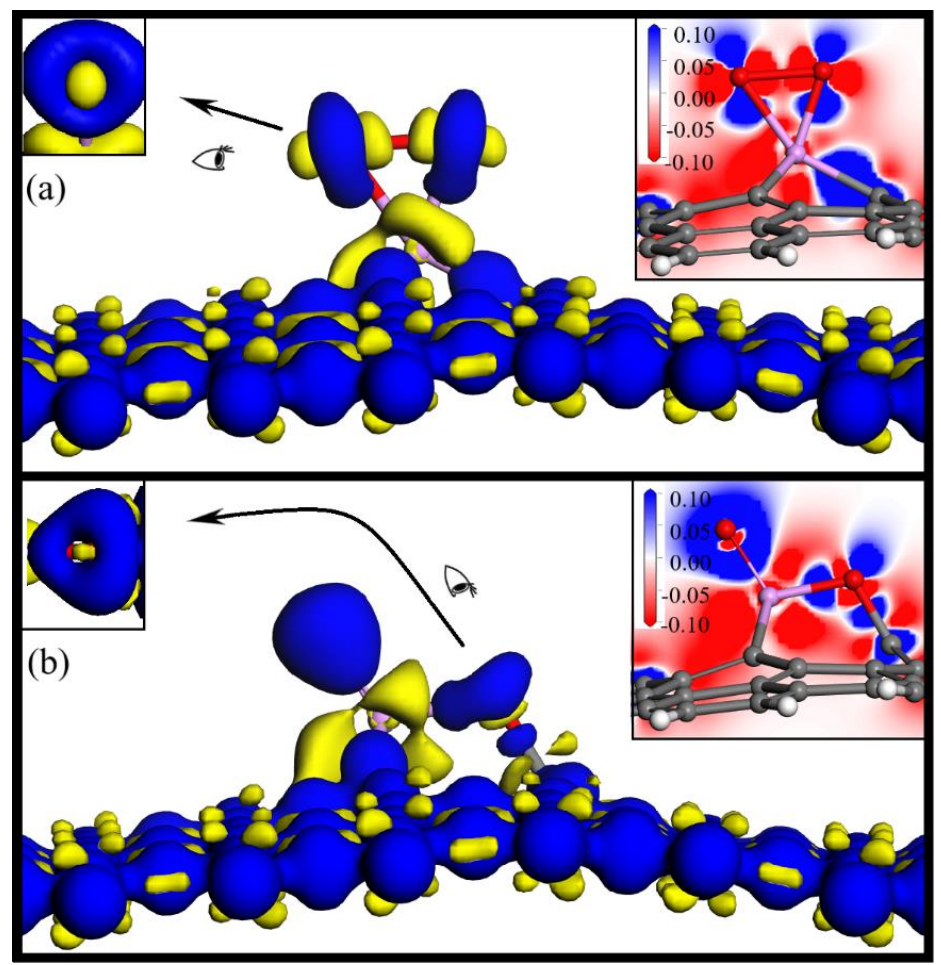

Figure 4: Charge deformation density of (a) the configuration of adsorbed oxygen and (b) the configuration of dissociated oxygen. Here, blue represents the increase of charge density, and yellow indicates the loss of charge density. The iso-surfaces level is $0.01 \mathrm{e} / \AA^{3}$. The upper right corner is a slice of charge deformation density.

reaction to form the first water molecule was divided into two steps (Figure 5). First, O-C bond was broken, and the $\mathrm{C}$ atom and $\mathrm{P}$ atom were bonded. Then, $\mathrm{OH}$ group detached from the substrate and combines with an introduced $\mathrm{H}$ atoms to form a water molecule. However, the reaction to form another $\mathrm{OH}$ group had a larger reaction barrier (Figure S4). 


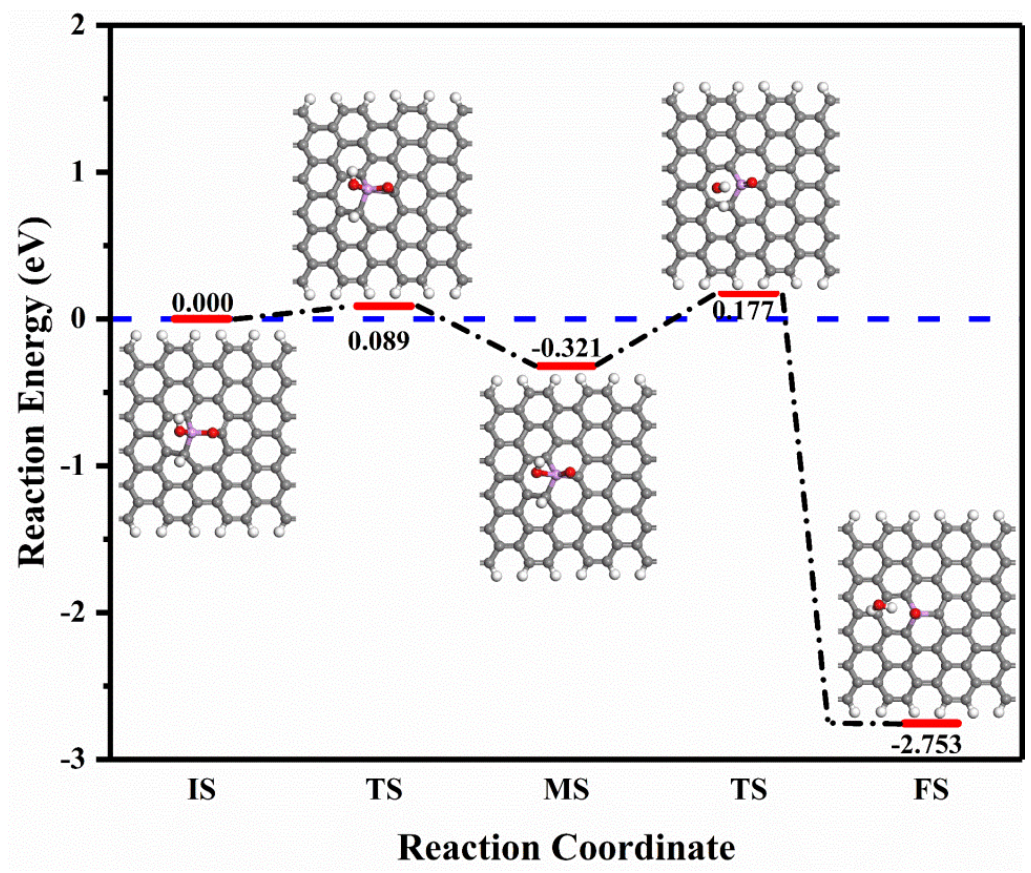

Figure 5: Structures of the initial state (left panel), transition state (middle panel), and final state (right panel) for the reaction: ${ }^{*} \mathrm{H}$ $+{ }^{*}\left(\mathrm{OH}+{ }^{*} \mathrm{O}\right) \rightarrow{ }^{*} \mathrm{H}+{ }^{*}(\mathrm{OH}+\mathrm{O}) \rightarrow{ }^{*} \mathrm{O}+\mathrm{H}_{2} \mathrm{O}$. The figure also includes the reaction heat and reaction barrier.

After the first $\mathrm{H}_{2} \mathrm{O}$ molecule was desorbed from PGNR, the remaining ${ }^{*} \mathrm{O}$ underwent two consecutive hydrogenation reactions, forming * $\mathrm{OH}$ (Figure S5) and another $\mathrm{H}_{2} \mathrm{O}$ molecule (Figure S6), respectively. However, all these hydrogenation process had a large reaction barrier. In particular, the last hydrogenation reaction corresponds to a reaction barrier of $2.047 \mathrm{eV}$. Hence, these reactions were also unlikely.

\section{B. The Association Mechanism}

In the following discussion, the reactions of association mechanism were considered. The system formed ${ }^{*} \mathrm{OOH}$ after the first hydrogenation reaction (Figure 6). However, the reaction barrier was higher than that of the direct dissociation reaction $\left({ }^{*} \mathrm{O}_{2} \rightarrow{ }^{*}\left(\mathrm{O}+{ }^{*} \mathrm{O}\right)\right) .{ }^{*} \mathrm{OOH}$ configuration was not stable. There were two easy-toproduce configurations.

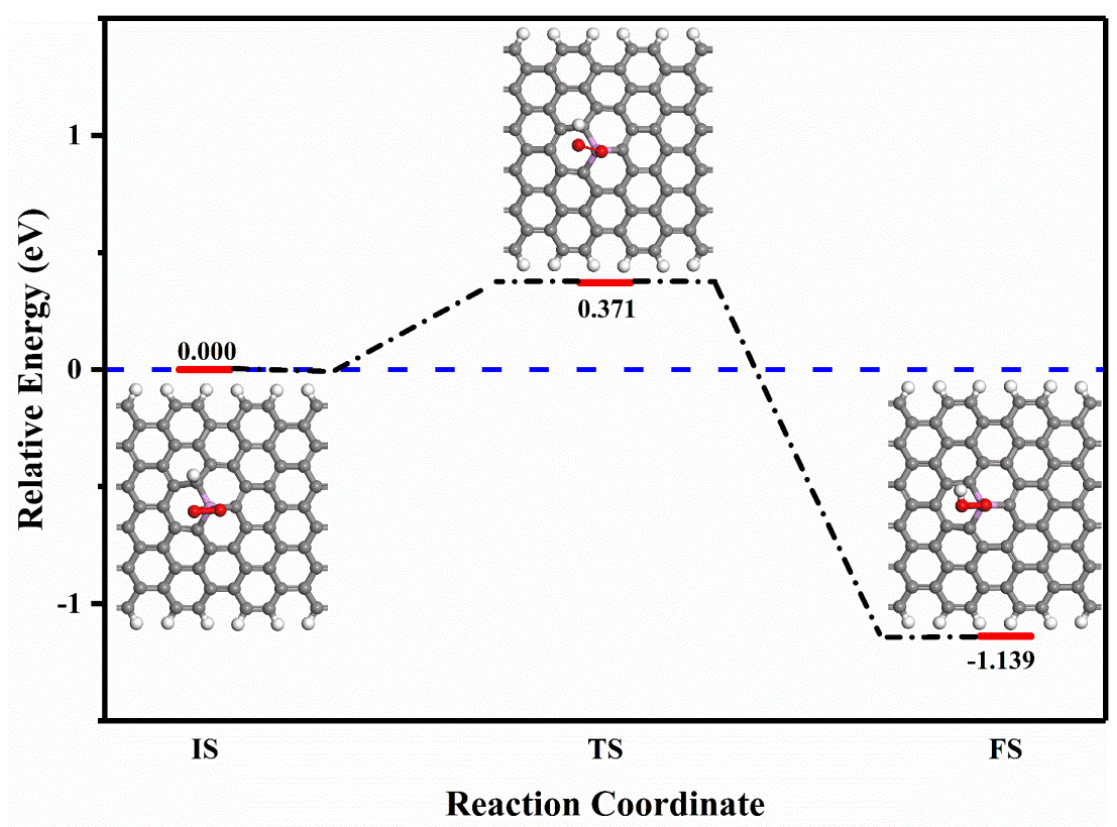

Figure 6: Structures of the initial state (left panel), transition state (middle panel), and final state (right panel) for the reaction: ${ }^{*} \mathrm{O}_{2}+{ }^{*} \mathrm{H} \rightarrow{ }^{*} \mathrm{OOH}$. The figure also includes the reaction heat and reaction barrier. 
For one possible conversion reaction, it could be divided into two reaction steps. Firstly, $\mathrm{O}-\mathrm{O}$ bond was broken, and $\mathrm{OH}$ group was bonded to $\mathrm{P}$ atom. Then the other $\mathrm{O}$ atom was bonded to adjacent carbon atom and was finally in the bridging position of the P-C bond. The reaction barriers of these reaction steps were $0.079 \mathrm{eV}$ and $0.035 \mathrm{eV}$, respectively (Figure 7). For the other possible conversion reaction, $\mathrm{O}-\mathrm{O}$ bond was still broken, and then $\mathrm{OH}$ group was bonded to the carbon atom of para position (relative to the $\mathrm{P}$ atom). This reaction with a reaction barrier of $0.076 \mathrm{eV}$ was very easy to occur (Figure 8). For the product of this reaction, its subsequent hydrogenation was considered. Hydrogenation may occur on the $\mathrm{O}$ atom adjacent to $\mathrm{P}$ atom or on the $\mathrm{O}$ atom adjacent to $\mathrm{C}$ atom (Figure $\mathrm{S} 7$ and S8). However, the reaction barriers of these reactions were not low.

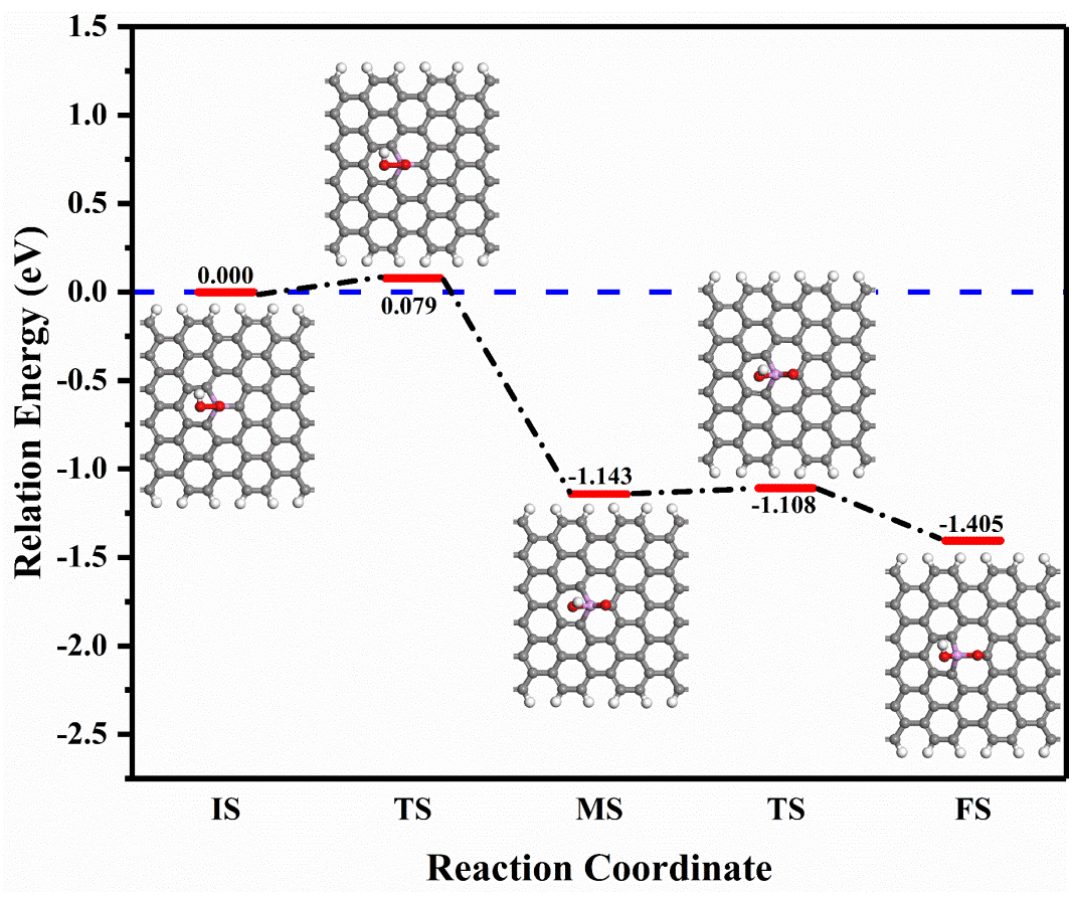

Figure 7: Structures of the initial state (left panel), transition state (middle panel), and final state (right panel) for the reaction: ${ }^{*} \mathrm{OOH} \rightarrow{ }^{*}(\mathrm{OH}+\mathrm{O}) \rightarrow{ }^{*}\left(\mathrm{OH}+{ }^{*} \mathrm{O}\right)$. The figure also includes the reaction heat and reaction barrier.

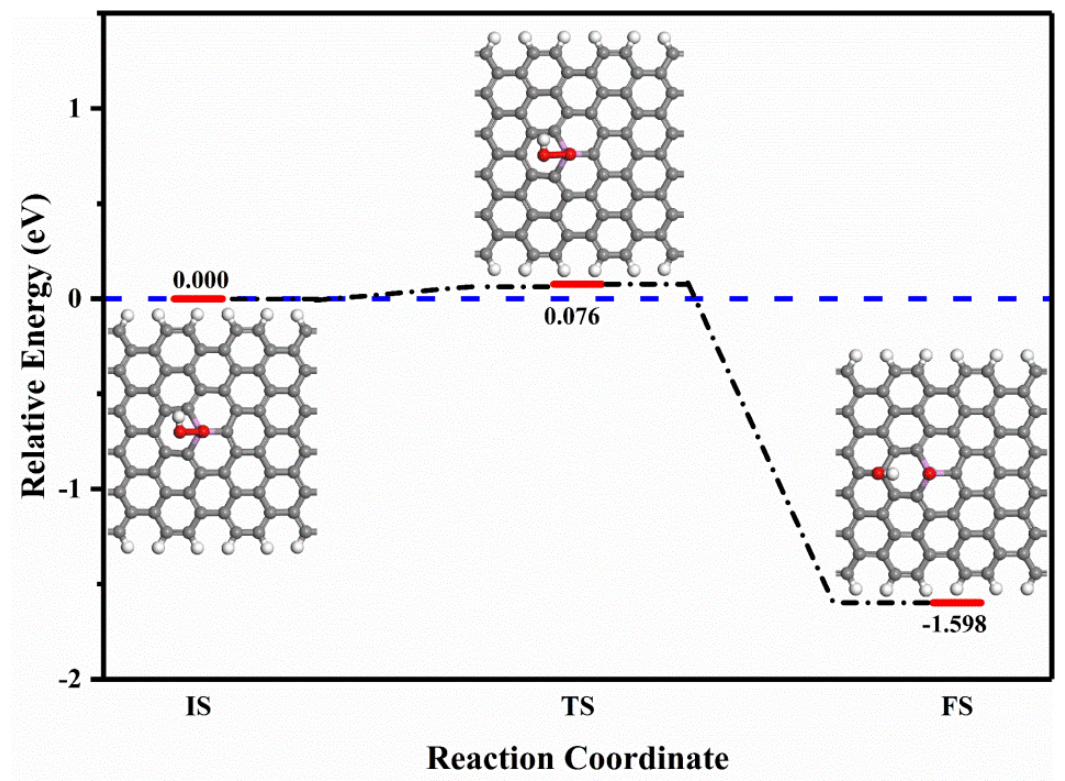

Figure 8: Structures of the initial state (left panel), transition state (middle panel), and final state (right panel) for the reaction: ${ }^{*} \mathrm{OOH} \rightarrow{ }^{*} \mathrm{OH}+{ }^{*} \mathrm{O}$. The figure also includes the reaction heat and reaction barrier. 
In addition, an MD simulation was performed on a ${ }^{*} \mathrm{OOH}$ configuration (Figure S9). The entire trajectory lasted 1 picosecond and was divided into 1000 steps. When the MD simulation proceeded to 300 steps, O-O bond became significantly longer and then broke. At this point, the system formed a ${ }^{*} \mathrm{O}$ configuration as well as a free $\mathrm{OH}$ group. This configuration was maintained throughout the subsequent steps. So the ${ }^{*} \mathrm{OOH}$ configuration is unstable and existed for less than 1 ps. Based on the reaction current density of a similar catalytic system [7], it can be speculated that the time interval for introducing $\mathrm{H}$ atoms is too long, so most of ${ }^{*} \mathrm{OOH}$ configurations cannot introduce $\mathrm{H}$ atoms due to their short lifespan. In addition, since ${ }^{*} \mathrm{OOH}$ is extremely unstable, hydrogen peroxide is hardly produced, which indicates that the ORR of the twoelectron pathway is also impossible. Summarizing the above calculation results, Figure 9 shows the ORR pathway of the PGNR considered in this paper. The ORR activity of PGNR is not ideal.

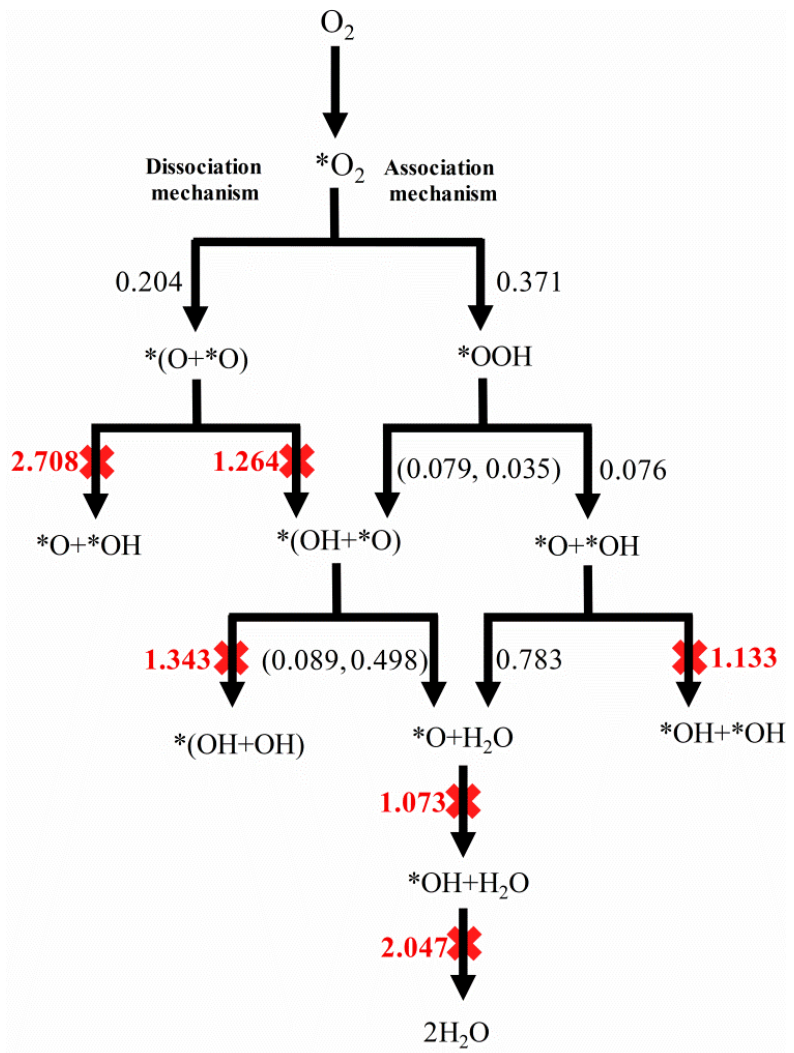

Figure 9: Overall oxygen reduction pathway considered here. The value is the lowest reaction barrier $(\mathrm{eV})$. For reactions with middle state, the numbers in parentheses indicate the energy barrier for each reaction step.

\subsection{Free Energy Diagram and Analysis}

The free energy of the reactions is discussed here. When calculating the free energy of these reactions, energy change caused by the introduction of hydrogen atoms cannot be ignored, which is different from the transition state search. Since the direct decomposition of adsorbed oxygen had a lower reaction barrier than the formation of ${ }^{*} \mathrm{OOH}$ intermediate, only the reaction path of the dissociation mechanism is considered here. Based on the CHE model, a ladder diagram of free energy is plotted according to these reaction steps listed above. Some hydrogenation reactions increase the free energy of the system, which indicates that some intermediate products are difficult to hydrogenate (Figure 10).

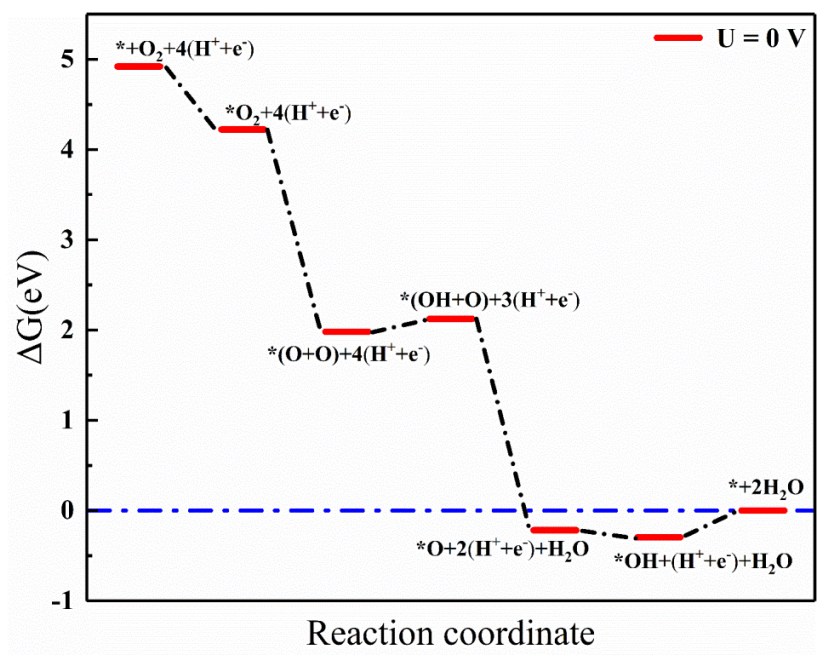

Figure 10: Free energy for the ORR pathway on the PGNR in an acidic environment $(\mathrm{pH}=0)$.

In all above cases, doping position is at the center. The fourth hydrogenation in ORR path is very difficult to occur. This reaction is endothermic and its reaction barrier is very large. Edge doping may vary. Consequently, this reaction on the edge-doping model was calculated. Unfortunately, the reaction was also endothermic (Figure S10).

P-doped graphene and graphene nanosheets have been experimentally prepared to have ORR activity under acidic or alkaline conditions [53-55]. However, the ORR activity of PGNR in this study seem to be poor. The reason may be that for the experimentally synthesized P-doped $\pi$-conjugated carbon material, the actual configuration is relatively complicated. Because some stable intermediates may persist. The oxidized $\mathrm{P}$ atom was found by detecting the synthesized P-doped graphene or graphene nanosheet [54, 56]. This indicates that the sample with the oxidized $\mathrm{P}$ atom can be stably present and is easy to be synthesized.

In addition, DFT calculations show that *O configuration has good stability compared to some configu- 
rations [47]. These configurations include three-coordinated PGNR (=PGNR) and three-coordinated *O configuration $\left(={ }^{*} \mathrm{O}\right)$, four-coordinated $P G N R$ and fourcoordinated ${ }^{*} \mathrm{O}$ configuration. The structure of threecoordinated ${ }^{*} \mathrm{O}$ configuration possess the only negative forming energy among these configurations.

Therefore, we take the attitude that $\mathrm{P}$ atom in PGNR may not be a valid ORR active site. Because the $P$ atom is easily oxidized, and the oxidation product is difficult to reduce. In addition, some configurations are very stable, such as ${ }^{*} \mathrm{O},{ }^{*} \mathrm{OH},{ }^{*}\left(\mathrm{O}+{ }^{*} \mathrm{O}\right)$, etc. The presence of these configurations complicates the properties of PGNR and thus the contribution of these configurations to ORR activity should not be ignored. Further work is underway to expound the ORR mechanism.

\section{CONCLUSIONS}

Base on DFT, we investigated the possible ORR pathways for PGNR with armchair edges under acidic conditions. Phosphorus atoms were used as active sites due to its strong adsorption of oxygen in this study. The $\mathrm{P}$ atom makes oxygen readily chemisorbed. The adsorbed oxygen molecules are easily dissociated. However, some intermediates are very stable, which is detrimental to the formation of the final product. At the same time, when $P$ atom is doped at the edge, the fourth hydrogenation reaction is still endothermic. Finally, combined with relevant research, the doped $\mathrm{P}$ atom is easily oxidized and the structures with oxidized $P$ atom are stable. It is speculated that PGNR may contain multiple stable configurations, which complicate the properties of PGNR. Certainly, for the structure of PGNR studied in our paper, it is arduous to achieve the effect of catalyzing ORR. Therefore, more attention needs to be paid to identifying active sites and studying the ORR mechanisms of these stable configurations.

\section{ACKNOWLEDGMENTS}

This work was supported by the Natural Science Foundation of Jiangxi Province (20202BAB214010), the Research Foundation of the Education Department of Jiangxi Province of China (grant no. GJJ180433), and the Open Funds of the State Key Laboratory of Metastable Materials Science and Technology (grant no. 201906).

\section{REFERENCES}

[1] I. Dincer, C. Acar, Review and evaluation of hydrogen production methods for better sustainability, Int. J. Hydrogen Energ. 40(34) (2015) 11094-11111.

https://doi.org/10.1016/j.ijhydene.2014.12.035
[2] Y. Jiao, Y. Zheng, M. Jaroniec, S.Z. Qiao, Design of electrocatalysts for oxygen- and hydrogen-involving energy conversion reactions, Chem. Soc. Rev. 44(8) (2015) 20602086.

https://doi.org/10.1039/C4CS00470A

[3] H.A. Gasteiger, N.M. Marković, Just a dream-or future reality?, Science 324(5923) (2009) 48-49.

https://doi.org/10.1126/science. 1172083

[4] M. Shao, Q. Chang, J.P. Dodelet, R. Chenitz, Recent Advances in Electrocatalysts for Oxygen Reduction Reaction, Chem. Rev. 116(6) (2016) 3594-657. https://doi.org/10.1021/acs.chemrev.5b00462

[5] Y. Nie, L. Li, Z. Wei, Recent advancements in Pt and Pt-free catalysts for oxygen reduction reaction, Chem. Soc. Rev. 44(8) (2015) 2168-201.

https://doi.org/10.1039/C4CS00484A

[6] C. Hu, L. Dai, Doping of Carbon Materials for Metal-Free Electrocatalysis, Adv. Mater. 31(7) (2019) 1804672. https://doi.org/10.1002/adma.201804672

[7] Y. Jiao, Y. Zheng, M. Jaroniec, S.Z. Qiao, Origin of the Electrocatalytic Oxygen Reduction Activity of GrapheneBased Catalysts: A Roadmap to Achieve the Best Performance, J. Am. Chem. Soc. 136(11) (2014) 4394-4403. https://doi.org/10.1021/ja500432h

[8] Y. Cheng, C. Xu, L. Jia, J.D. Gale, L. Zhang, C. Liu, P.K. Shen, S.P. Jiang, Pristine carbon nanotubes as non-metal electrocatalysts for oxygen evolution reaction of water splitting, Appl. Catal. B: Environ. 163 (2015) 96-104. https://doi.org/10.1016/j.apcatb.2014.07.049

[9] M.D. Esrafili, E. Vessally, $\mathrm{N}_{2} \mathrm{O}+\mathrm{CO}$ reaction over single $\mathrm{Ga}$ or Ge atom embedded graphene: A DFT study, Surf. Sci. 667 (2018) 105-111.

https://doi.org/10.1016/j.susc.2017.10.001

[10] J.Y. Cheon, J.H. Kim, J.H. Kim, K.C. Goddeti, J.Y. Park, S.H. Joo, Intrinsic relationship between enhanced oxygen reduction reaction activity and nanoscale work function of doped carbons, J. Am. Chem. Soc. 136(25) (2014) 8875-8. https://doi.org/10.1021/ja503557x

[11] Z. Xie, M. Chen, S.G. Peera, C. Liu, H. Yang, X. Qi, U.P. Kumar, T. Liang, Theoretical Study on a Nitrogen-Doped Graphene Nanoribbon with Edge Defects as the Electrocatalyst for Oxygen Reduction Reaction, ACS Omega 5(10) (2020) 5142-5149.

https://doi.org/10.1021/acsomega.9b04146

[12] Z. Liang, M. Luo, M. Chen, C. Liu, S.G. Peera, X. Qi, J. Liu, U.P. Kumar, T.L.T. Liang, Evaluating the catalytic activity of transition metal dimers for the oxygen reduction reaction, J. Colloid Interf. Sci. 568 (2020) 54-62. https://doi.org/10.1016/j.jcis.2020.02.034

[13] S. Geng, J. Liu, C. Wang, L. Dong, T. Liang, Experimental analysis and theoretical studies by density functional theory of aminopropyl-modified ordered mesoporous carbon, Appl. Surf. Sci. 351 (2015) 911-919.

https://doi.org/10.1016/j.apsusc.2015.06.034

[14] J. Liu, C. Wang, L. Dong, T. Liang, Study on the Recycling of Nuclear Graphite after Micro-Oxidation, Nucl. Eng. Technol. 48(1) (2016) 182-188.

https://doi.org/10.1016/j.net.2015.08.007

[15] L. Dai, Y. Xue, L. Qu, H.-J. Choi, J.-B. Baek, Metal-free catalysts for oxygen reduction reaction, Chem. Rev. 115(11) (2015) 4823-92. https://doi.org/10.1021/cr5003563

[16] S.G. Peera, A.K. Sahu, A. Arunchander, S.D. Bhat, J. Karthikeyan, P. Murugan, Nitrogen and fluorine co-doped graphite nanofibers as high durable oxygen reduction catalyst in acidic media for polymer electrolyte fuel cells, Carbon 93 (2015) 130-142.

https://doi.org/10.1016/j.carbon.2015.05.002 
[17] S. Agnoli, M. Favaro, Doping graphene with boron: a review of synthesis methods, physicochemical characterization, and emerging applications, J. Mater. Chem. A 4(14) (2016) 50025025 .

https://doi.org/10.1039/C5TA10599D

[18] D.Y. Yeom, W. Jeon, N.D. Tu, S.Y. Yeo, S.S. Lee, B.J. Sung, H. Chang, J.A. Lim, H. Kim, High-concentration boron doping of graphene nanoplatelets by simple thermal annealing and their supercapacitive properties, Sci. Rep. 5 (2015) 9817. https://doi.org/10.1038/srep09817

[19] R. Vishwakarma, G. Kalita, S.M. Shinde, Y. Yaakob, C. Takahashi, M. Tanemura, Structure of nitrogen-doped graphene synthesized by combination of imidazole and melamine solid precursors, Mater. Lett. 177 (2016) 89-93. https://doi.org/10.1016/j.matlet.2016.04.155

[20] A. Arunchander, S.G. Peera, S.K. Panda, S. Chellammal, A.K. Sahu, Simultaneous co-doping of $\mathrm{N}$ and $\mathrm{S}$ by a facile insitu polymerization of 6-N,N-dibutylamine-1,3,5-triazine-2,4dithiol on graphene framework: An efficient and durable oxygen reduction catalyst in alkaline medium, Carbon 118 (2017) 531-544.

https://doi.org/10.1016/j.carbon.2017.03.093

[21] J. Wu, C. Jin, Z. Yang, J. Tian, R. Yang, Synthesis of phosphorus-doped carbon hollow spheres as efficient metalfree electrocatalysts for oxygen reduction, Carbon 82 (2015) 562-571.

https://doi.org/10.1016/j.carbon.2014.11.008

[22] M. Klingele, C. Pham, K.R. Vuyyuru, B. Britton, S. Holdcroft, A. Fischer, S. Thiele, Sulfur doped reduced graphene oxide as metal-free catalyst for the oxygen reduction reaction in anion and proton exchange fuel cells, Electrochem. Commun. 77 (2017) 71-75. https://doi.org/10.1016/i.elecom.2017.02.015

[23] J.J. Spivey, K.S. Krishna, C.S.S.R. Kumar, K.M. Dooley, J.C. Flake, L.H. Haber, Y. Xu, M.J. Janik, S.B. Sinnott, Y.-T. Cheng, T. Liang, D.S. Sholl, T.A. Manz, U. Diebold, G.S. Parkinson, D.A. Bruce, P. de Jongh, Synthesis, Characterization, and Computation of Catalysts at the Center for Atomic-Level Catalyst Design, J. Phys. Chem. C 118(35) (2014) 20043-20069.

https://doi.org/10.1021/jp502556u

[24] S.H. Noh, C. Kwon, J. Hwang, T. Ohsaka, B.-J. Kim, T.-Y. Kim, Y.-G. Yoon, Z. Chen, M.H. Seo, B. Han, Self-assembled nitrogen-doped fullerenes and their catalysis for fuel cell and rechargeable metal-air battery applications, Nanoscale 9(22) (2017) 7373-7379. https://doi.org/10.1039/C7NR00930E

[25] X. Hou, Q. Hu, P. Zhang, J. Mi, Oxygen reduction reaction on nitrogen-doped graphene nanoribbons: A density functional theory study, Chem. Phys. Lett. 663 (2016) 123-127. https://doi.org/10.1016/j.cplett.2016.10.003

[26] M.D. Esrafili, Nitrogen-doped $(6,0)$ carbon nanotubes: A comparative DFT study based on surface reactivity descriptors, Comput. Theor. Chem. 1015(7) (2013) 1-7. https://doi.org/10.1016/j.comptc.2013.04.003

[27] L. Zhang, J. Niu, L. Dai, Z. Xia, Effect of Microstructure of Nitrogen-Doped Graphene on Oxygen Reduction Activity in Fuel Cells, Langmuir 28(19) (2012) 7542-7550. https://doi.org/10.1021/la2043262

[28] X.H. Zheng, L.F. Huang, X.L. Wang, J. Lan, Z. Zeng, Band gap engineering in armchair-edged graphene nanoribbons by edge dihydrogenation, Comp. Mater. Sci. 62 (2012) 9398.

\section{https://doi.org/10.1016/j.commatsci.2012.05.022}

[29] L. Zhang, Z. Xia, Mechanisms of Oxygen Reduction Reaction on Nitrogen-Doped Graphene for Fuel Cells, J. Phys. Chem. C 115(22) (2011) 11170-11176.

https://doi.org/10.1021/jp201991j
[30] Y. Wang, J. Mao, X. Meng, L. Yu, D. Deng, X. Bao, Catalysis with Two-Dimensional Materials Confining Single Atoms: Concept, Design, and Applications, Chem. Rev. 119(3) (2019) 1806-1854. https://doi.org/10.1021/acs.chemrev.8b00501

[31] K.V. Bets, B.I. Yakobson, Spontaneous Twist and Intrinsic Instabilities of Pristine Graphene Nanoribbons, Nano Res. 2(2) (2009) 161-166. https://doi.org/10.1007/s12274-009-9015-x

[32] H. Jin, C. Guo, X. Liu, J. Liu, A. Vasileff, Y. Jiao, Y. Zheng, S.Z. Qiao, Emerging Two-Dimensional Nanomaterials for Electrocatalysis, Chem. Rev. 118(13) (2018) 6337-6408. https://doi.org/10.1021/acs.chemrev.7b00689

[33] B. Delley, From molecules to solids with the DMol3 approach, J. Chem. Phys. 113(18) (2000) 7756-7764. https://doi.org/10.1063/1.1316015

[34] B. Delley, An all-electron numerical method for solving the local density functional for polyatomic molecules, J. Chem. Phys. 92(1) (1990) 508-517. https://doi.org/10.1063/1.458452

[35] J.P. Perdew, K. Burke, M. Ernzerhof, Generalized Gradient Approximation Made Simple, Phys. Rev. Lett. 77(18) (1996) 3865.

https://doi.org/10.1103/PhysRevLett.77.3865

[36] S. Grimme, Semiempirical GGA-type density functional constructed with a long-range dispersion correction, J. Comput. Chem. 27(15) (2006) 1787-99.

https://doi.org/10.1002/jcc.20495

[37] A. Klamt, G. Schüürmann, COSMO: a new approach to dielectric screening in solvents with explicit expressions for the screening energy and its gradient, J. Chem. Soc., Perkin Trans. 2 (5) (1993) 799-805.

https://doi.org/10.1039/P29930000799

[38] B. Delley, The conductor-like screening model for polymers and surfaces, Mol. Simulat. 32(2) (2006) 117-123.

https://doi.org/10.1080/08927020600589684

[39] R.S. Mulliken, Electronic Population Analysis on LCAO-MO Molecular Wave Functions. I, J. Chem. Phys. 23(10) (1955) 1833-1840.

https://doi.org/10.1063/1.1740588

[40] T. A.Halgren, W. N.Lipscomb, The synchronous-transit method for determining reaction pathways and locating molecular transition states, Chem. Phys. Lett. 49(2) (1997) 225-232.

https://doi.org/10.1016/0009-2614(77)80574-5

[41] A. Sahu, G. Selvarani, S. Bhat, S. Pitchumani, P. Sridhar, A. Shukla, N. Narayanan, A. Banerjee, N. Chandrakumar, Effect of varying poly(styrene sulfonic acid) content in poly(vinyl alcohol)-poly(styrene sulfonic acid) blend membrane and its ramification in hydrogen-oxygen polymer electrolyte fuel cells, J. Membrane Sci. 319(1-2) (2008) 298-305. https://doi.org/10.1016/j.memsci.2008.04.004

[42] J.A. Keith, T. Jacob, Theoretical Studies of PotentialDependent and Competing Mechanisms of the Electrocatalytic Oxygen Reduction Reaction on $\mathrm{Pt}(111)$, Angew. Chem. Int. Ed. 49(49) (2010) 9521-9525. https://doi.org/10.1002/anie.201004794

[43] A.A. Peterson, F. Abild-Pedersen, F. Studt, J. Rossmeisl, J.K Nørskov, How copper catalyzes the electroreduction of carbon dioxide into hydrocarbon fuels, Energ. Environ. Sci. 3(9) (2010) 1311-1315. https://doi.org/10.1039/c0ee00071j

[44] J.K. Nørskov, J. Rossmeisl, A. Logadottir, L. Lindqvist, J.R. Kitchin, T. Bligaard, H. Jónsson, Origin of the Overpotential for Oxygen Reduction at a Fuel-Cell Cathode, J. Phys. Chem. B 108(46) (2004) 17886-17892. https://doi.org/10.1021/jp047349 
[45] H. Wang, H. Wang, Y. Chen, Y. Liu, J. Zhao, Q. Cai, X. Wang, Phosphorus-doped graphene and $(8,0)$ carbon nanotube: Structural, electronic, magnetic properties, and chemical reactivity, Appl. Surf. Sci. 273 (2013) 302-309. https://doi.org/10.1016/j.apsusc.2013.02.035

[46] J. Dai, J. Yuan, Modulating the electronic and magnetic structures of P-doped graphene by molecule doping, J. Phys. Condens. Matt. 22(22) (2010) 225501. https://doi.org/10.1088/0953-8984/22/22/225501

[47] N. Yang, X. Zheng, L. Li, J. Li, Z. Wei, Influence of Phosphorus Configuration on Electronic Structure and Oxygen Reduction Reactions of Phosphorus-Doped Graphene, J. Phys. Chem. C 121(35) (2017) 19321-19328. https://doi.org/10.1021/acs.jpcc.7b06748

[48] E. Cruz-Silva, Z.M. Barnett, B.G. Sumpter, V. Meunier, Structural, magnetic, and transport properties of substitutionally doped graphene nanoribbons from first principles, Phys. Rev. B 83(15) (2011) 155445. https://doi.org/10.1103/PhysRevB.83.155445

[49] Y. Ji, H. Dong, C. Liu, Y. Li, The progress of metal-free catalysts for the oxygen reduction reaction based on theoretical simulations, J. Mater. Chem. A 6(28) (2018) 13489-13508. https://doi.org/10.1039/C8TA02985G

[50] L. Wang, H. Dong, Z. Guo, L. Zhang, T. Hou, Y. Li, Potential Application of Novel Boron-Doped Graphene Nanoribbon as Oxygen Reduction Reaction Catalyst, J. Phys. Chem. C 120(31) (2016) 17427-17434. https://doi.org/10.1021/acs.jpcc.6b04639
[51] X. Zhang, Z. Lu, Z. Fu, Y. Tang, D. Ma, Z. Yang, The mechanisms of oxygen reduction reaction on phosphorus doped graphene: A first-principles study, J. Power Sources 276 (2015) 222-229.

https://doi.org/10.1016/j.jpowsour.2014.11.105

[52] B. He, J. Shen, D. Ma, Z. Lu, Z. Yang, Boron-Doped C3N Monolayer as a Promising Metal-Free Oxygen Reduction Reaction Catalyst: A Theoretical Insight, J. Phys. Chem. C 122(35) (2018) 20312-20322.

https://doi.org/10.1021/acs.jpcc.8b05171

[53] Z. Liu, F. Peng, H. Wang, H. Yu, W. Zheng, X. Wei, Preparation of phosphorus-doped carbon nanospheres and their electrocatalytic performance for $\mathrm{O} 2$ reduction, J. Nat. Gas Chem. 21(3) (2012) 257-264.

https://doi.org/10.1016/S1003-9953(11)60362-9

[54] R. Li, Z. Wei, X. Gou, W. Xu, Phosphorus-doped graphene nanosheets as efficient metal-free oxygen reduction electrocatalysts, RSC Adv. 3(25) (2013) 9978. https://doi.org/10.1039/c3ra41079j

[55] Z.W. Liu, F. Peng, H.J. Wang, H. Yu, W.X. Zheng, J. Yang, Phosphorus-doped graphite layers with high electrocatalytic activity for the $\mathrm{O} 2$ reduction in an alkaline medium, Angewandte Chemie 50(14) (2011) 3257-61. https://doi.org/10.1002/anie.201006768

[56] Y. Jiao, Y. Zheng, K. Davey, S.Z. Qiao, Activity origin and catalyst design principles for electrocatalytic hydrogen evolution on heteroatom-doped graphene, Nat. Energy 1(10) (2016) 16130.

https://doi.org/10.1038/nenergy.2016.130

DOI: https://doi.org/10.31875/2410-4701.2020.07.03

(c) 2020 Xie et al.; Zeal Press.

This is an open access article licensed under the terms of the Creative Commons Attribution Non-Commercial License (http://creativecommons.org/licenses/by-nc/3.0/) which permits unrestricted, non-commercial use, distribution and reproduction in any medium, provided the work is properly cited. 


\section{SUPPORTING INFORMATION}

(a)

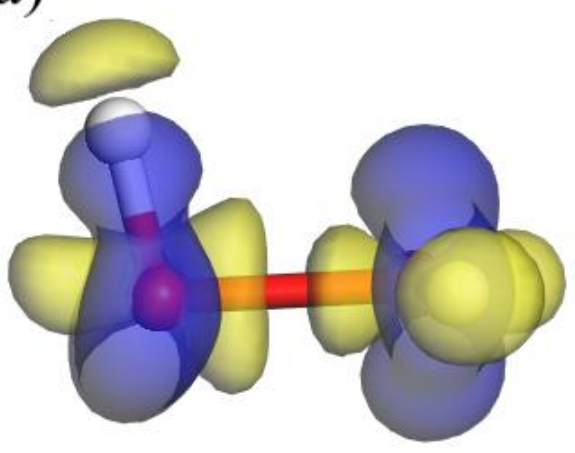

(b)

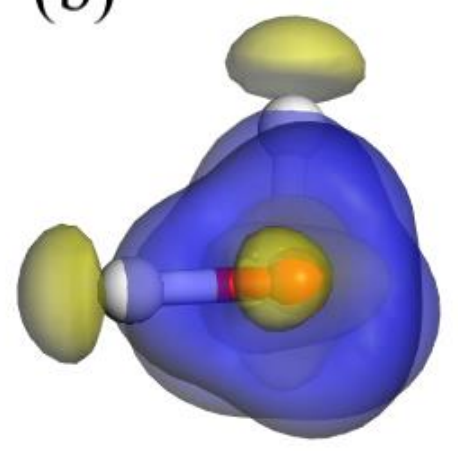

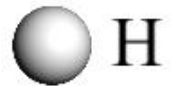

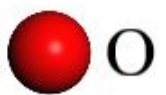

Figure S11: Charge deformation density of hydrogen peroxide, (a) front view and (b) side view.

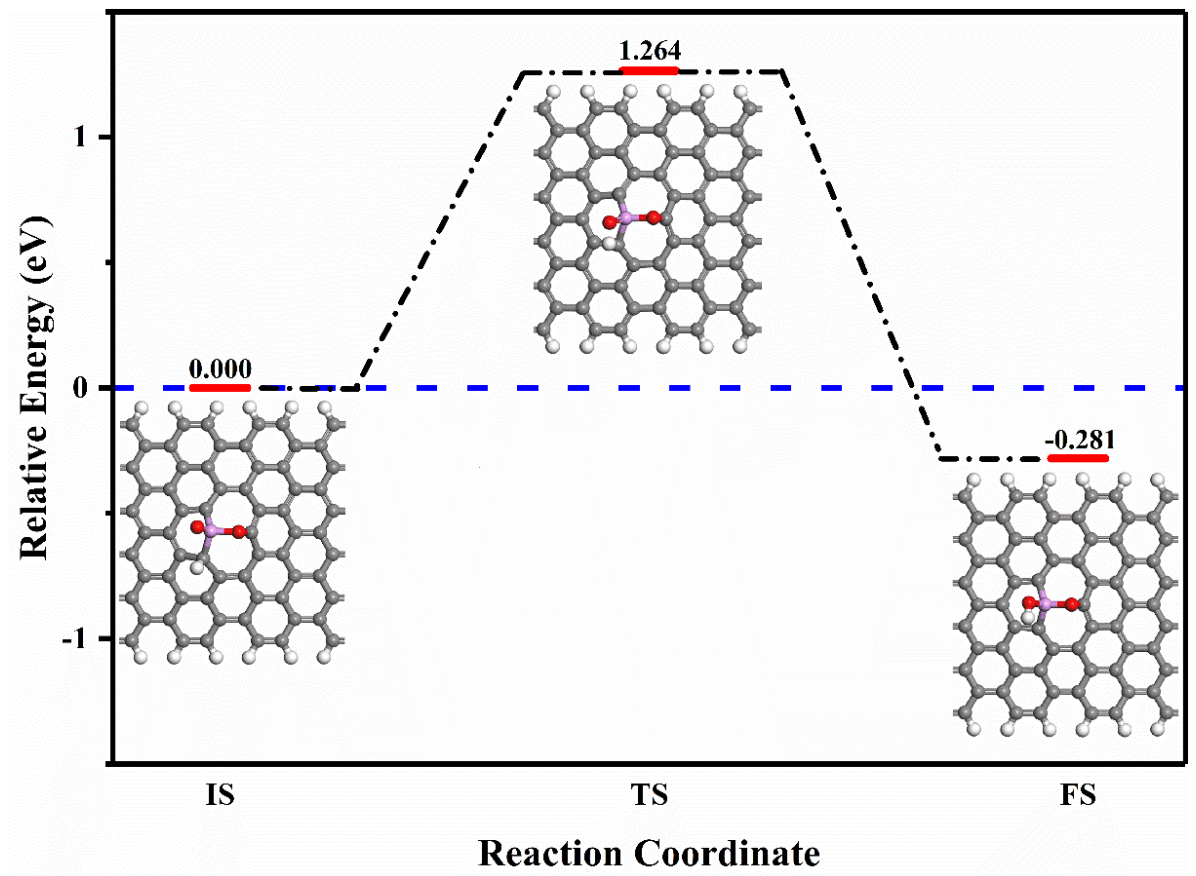

Figure S12: Structures of the initial state (left panel), transition state (middle panel), and final state (right panel) for the reaction: ${ }^{*} \mathrm{H}+{ }^{*}\left(\mathrm{O}+{ }^{*} \mathrm{O}\right) \rightarrow{ }^{*}\left(\mathrm{OH}+{ }^{*} \mathrm{O}\right)$. The figure also includes the reaction heat and reaction barrier. 


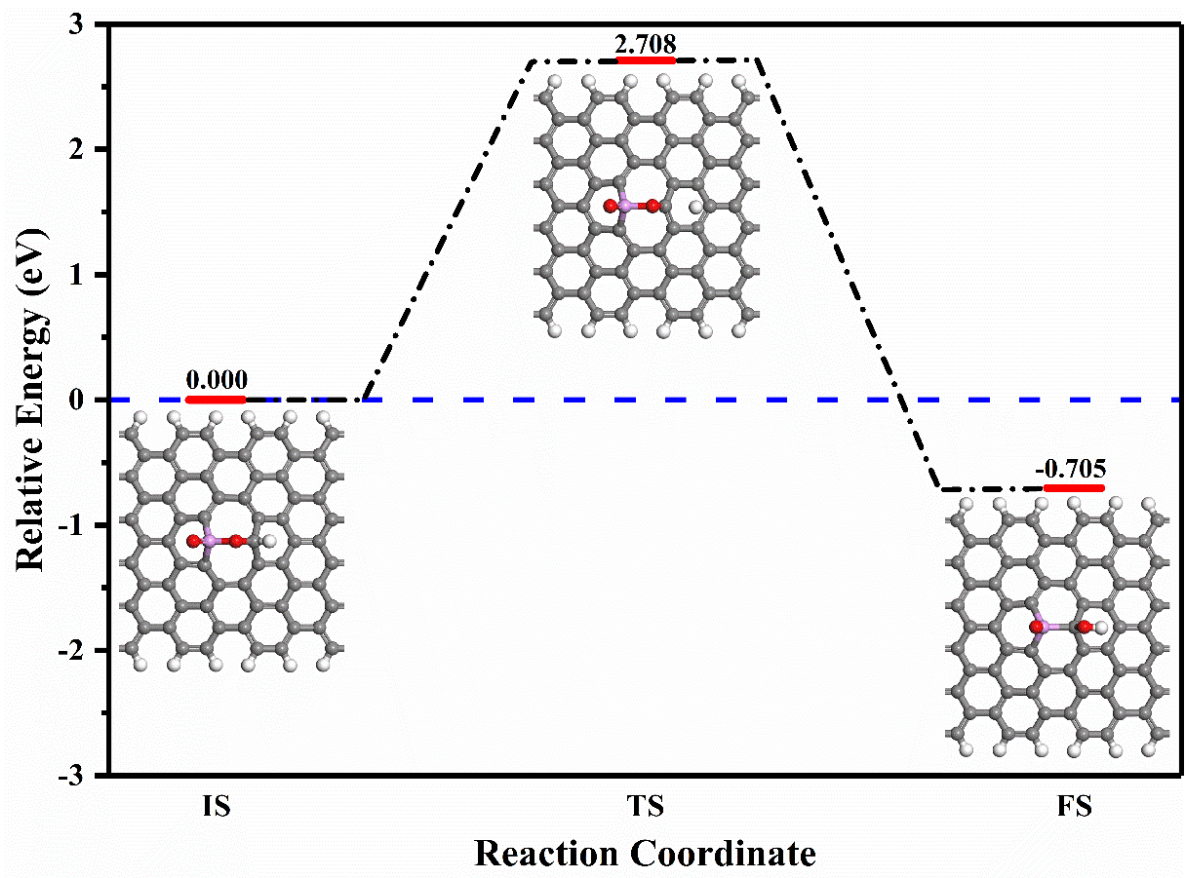

Figure S13: Structures of the initial state (left panel), transition state (middle panel), and final state (right panel) for the reaction: ${ }^{*}\left(\mathrm{O}+{ }^{*} \mathrm{O}\right)+{ }^{*} \mathrm{H} \rightarrow{ }^{*} \mathrm{O}+{ }^{*} \mathrm{OH}$. The figure also includes the reaction heat and reaction barrier.

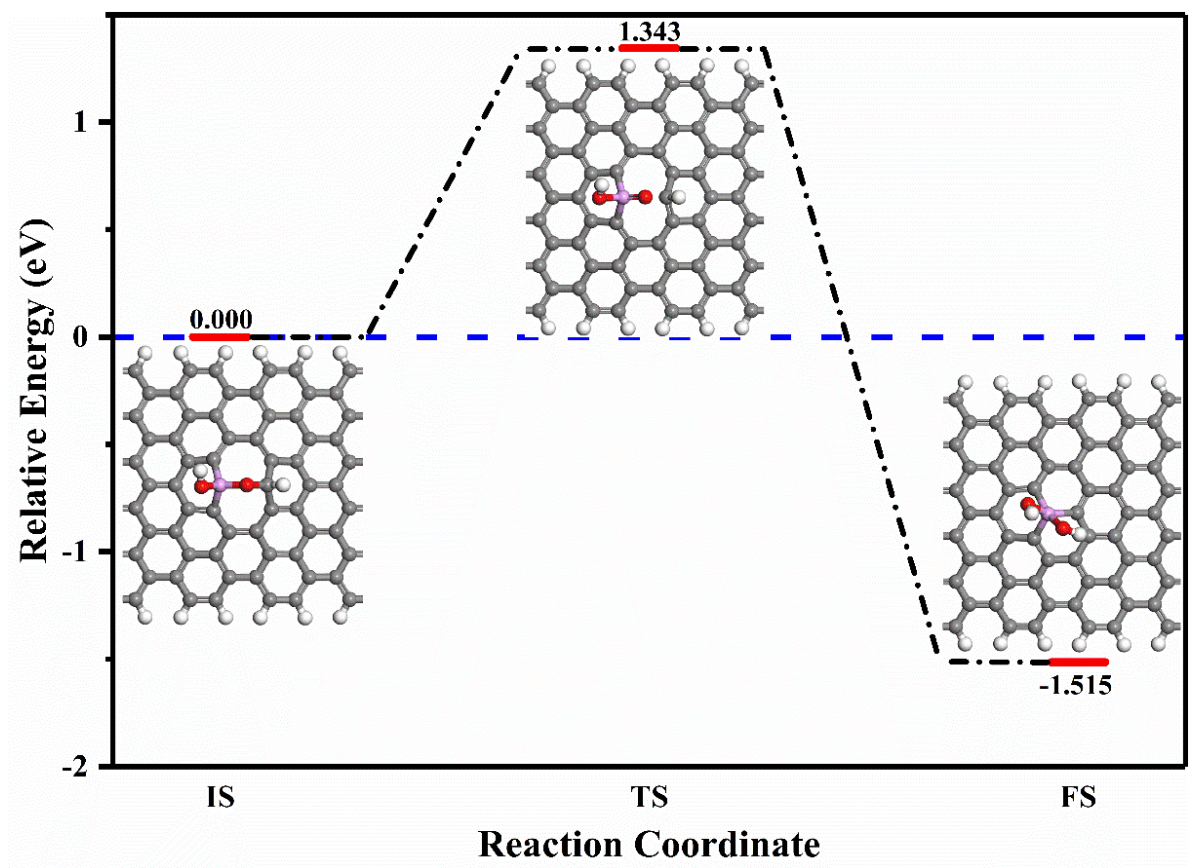

Figure S14: Structures of the initial state (left panel), transition state (middle panel), and final state (right panel) for the reaction: ${ }^{*}\left(\mathrm{OH}+{ }^{*} \mathrm{O}\right)+{ }^{*} \mathrm{H} \rightarrow{ }^{*}(\mathrm{OH}+\mathrm{OH})$. The figure also includes the reaction heat and reaction barrier. 


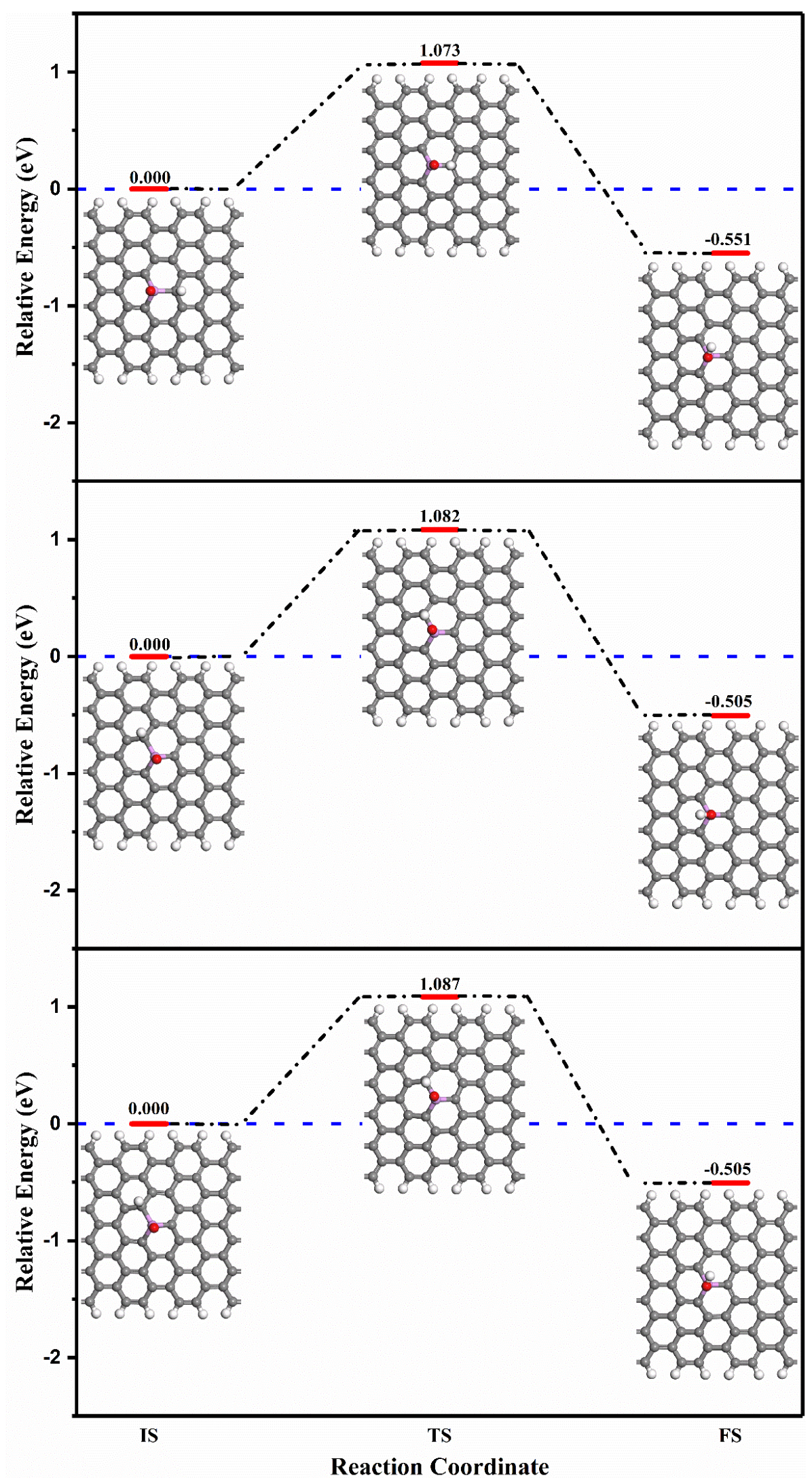

Figure S15: Structures of the initial state (left panel), transition state (middle panel), and final state (right panel) for the reaction: ${ }^{*} \mathrm{O}+{ }^{*} \mathrm{H} \rightarrow{ }^{*} \mathrm{OH}$. The figure also includes the reaction heat and reaction barrier. 


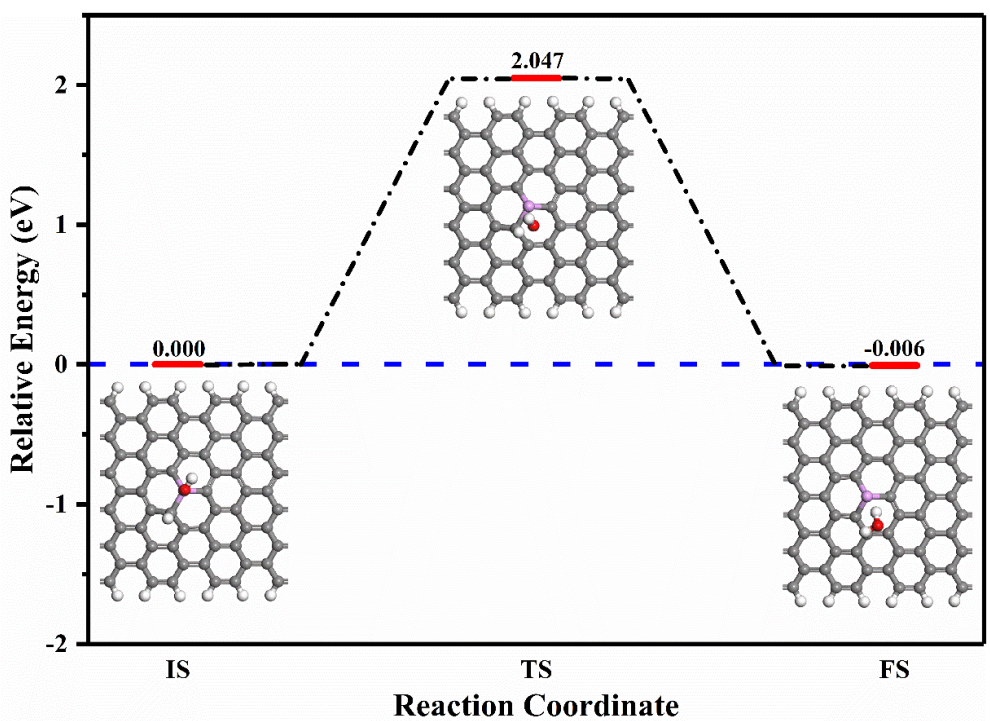

Figure S16: Structures of the initial state (left panel), transition state (middle panel), and final state (right panel) for the reaction: ${ }^{*} \mathrm{H}+{ }^{*} \mathrm{OH} \rightarrow \mathrm{H}_{2} \mathrm{O}$. The figure also includes the reaction heat and reaction barrier.

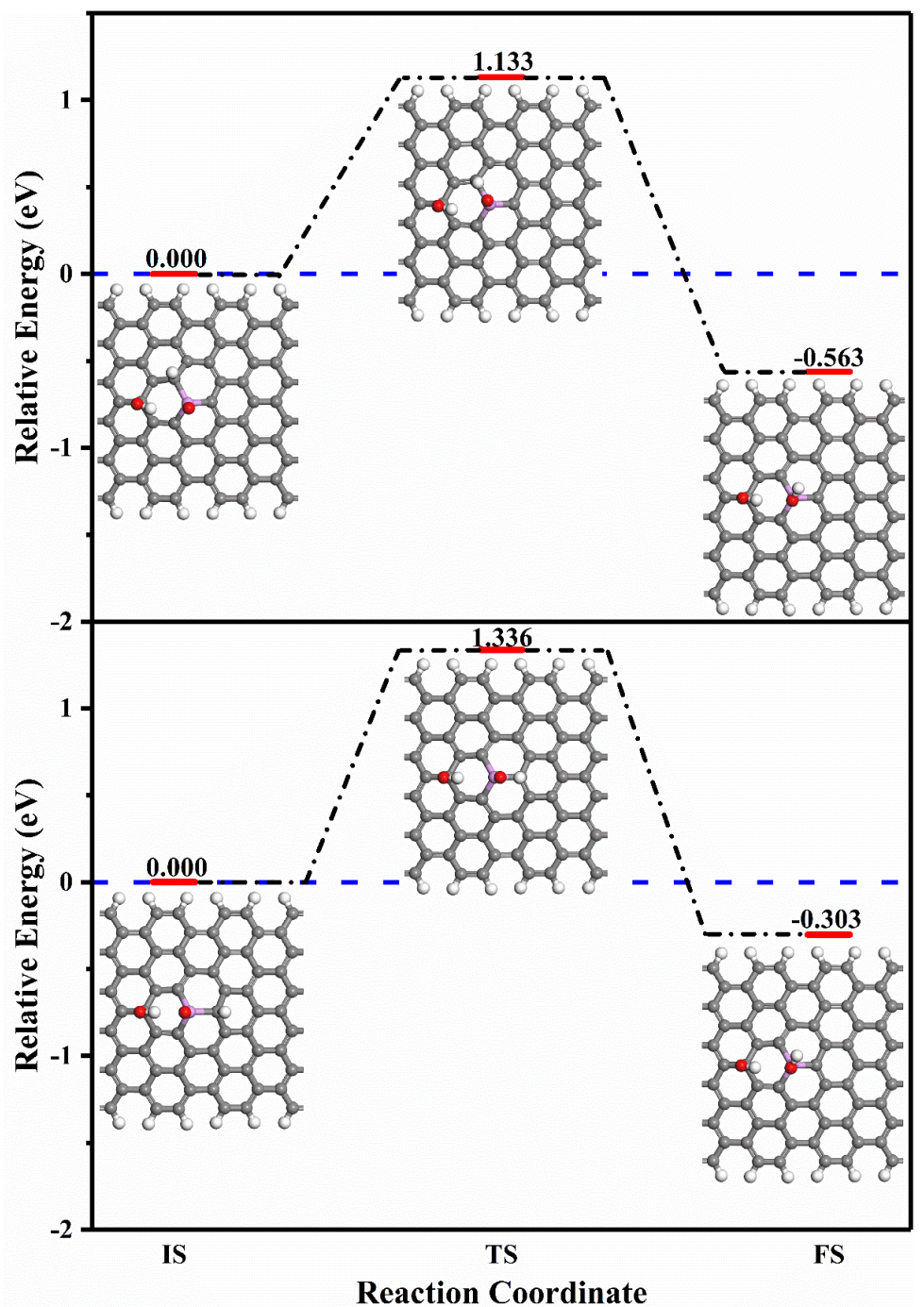

Figure S17: Structures of the initial state (left panel), transition state (middle panel), and final state (right panel) for the reaction: ${ }^{*} \mathrm{OH}+{ }^{*} \mathrm{O}+{ }^{*} \mathrm{H} \rightarrow{ }^{*} \mathrm{OH}+{ }^{*} \mathrm{OH}$. The figure also includes the reaction heat and reaction barrier. 


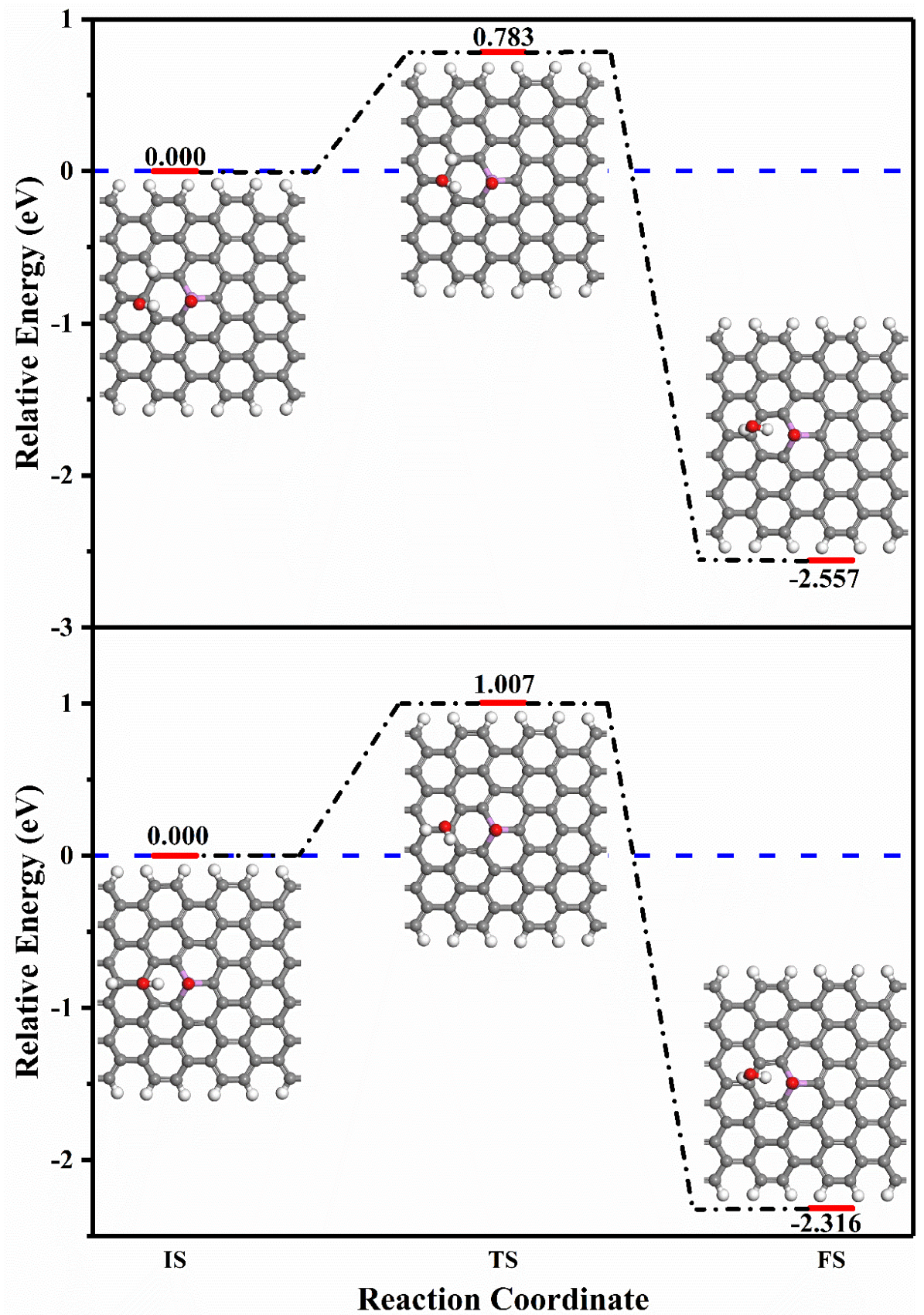

Figure S18: Structures of the initial state (left panel), transition state (middle panel), and final state (right panel) for the reaction: ${ }^{*} \mathrm{OH}+{ }^{*} \mathrm{O}+{ }^{*} \mathrm{H} \rightarrow{ }^{*} \mathrm{O}+\mathrm{H}_{2} \mathrm{O}$. The figure also includes the reaction heat and reaction barrier. 


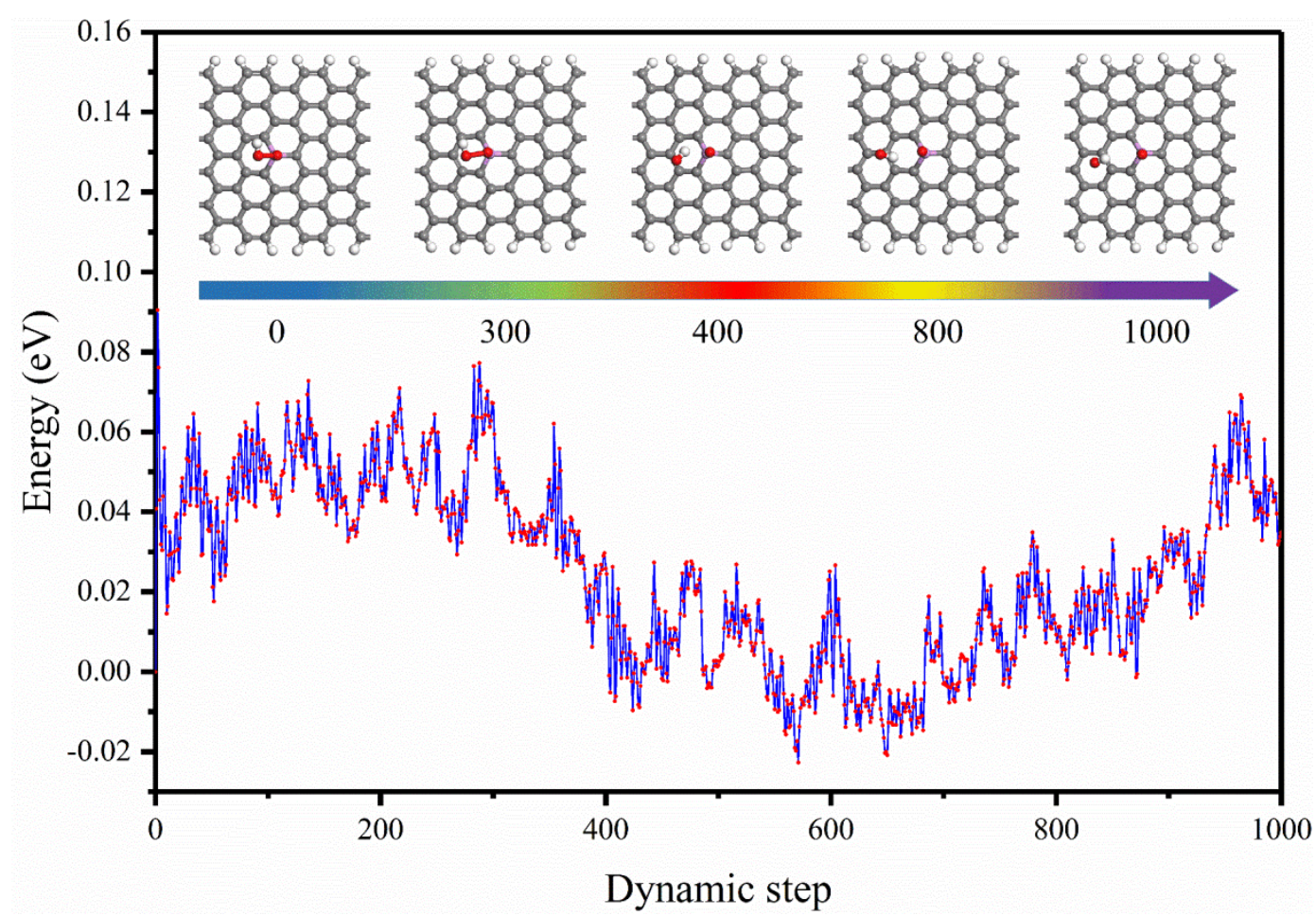

Figure S19: MD simulation for ${ }^{*} \mathrm{OOH}$ at the temperature of $60^{\circ} \mathrm{C}$ in the NVT ensemble. The entire trajectory lasted 1 picosecond and was divided into 1000 steps.
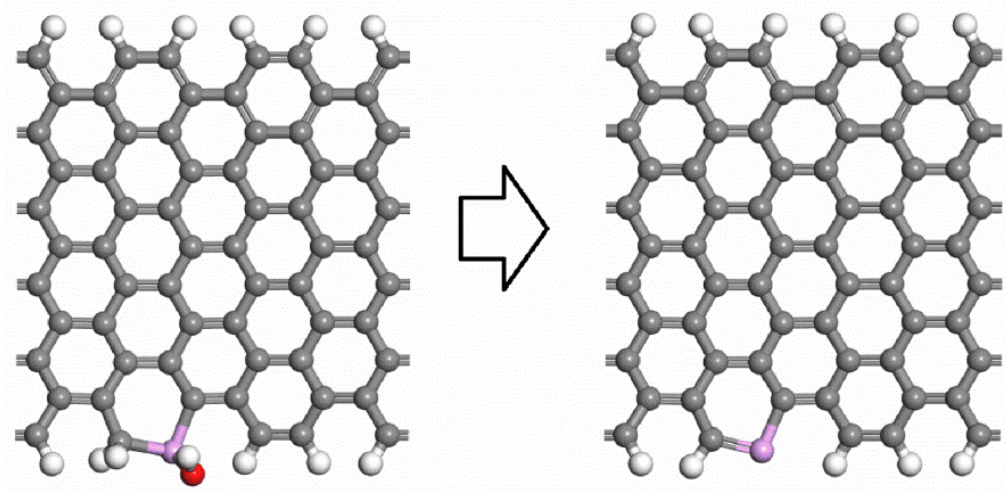

Figure S20: Reactant configuration and product configuration of the final dehydration reaction of edge P-doped PGNR 


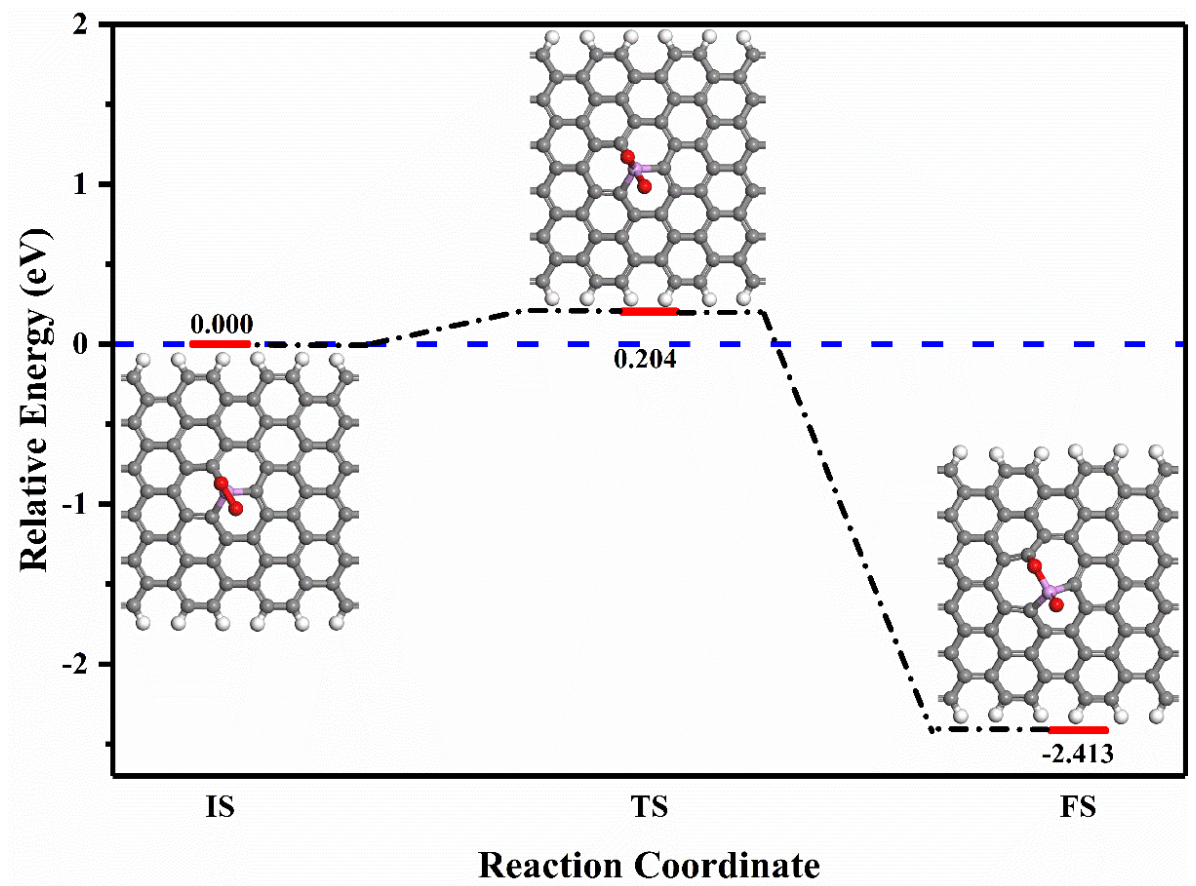

Figure S21: Structures of the initial state (left panel), transition state (middle panel), and final state (right panel) for the reaction: ${ }^{*} \mathrm{O}_{2} \rightarrow{ }^{*}\left(\mathrm{O}+{ }^{*} \mathrm{O}\right)$. The figure also includes the reaction heat and reaction barrier. 


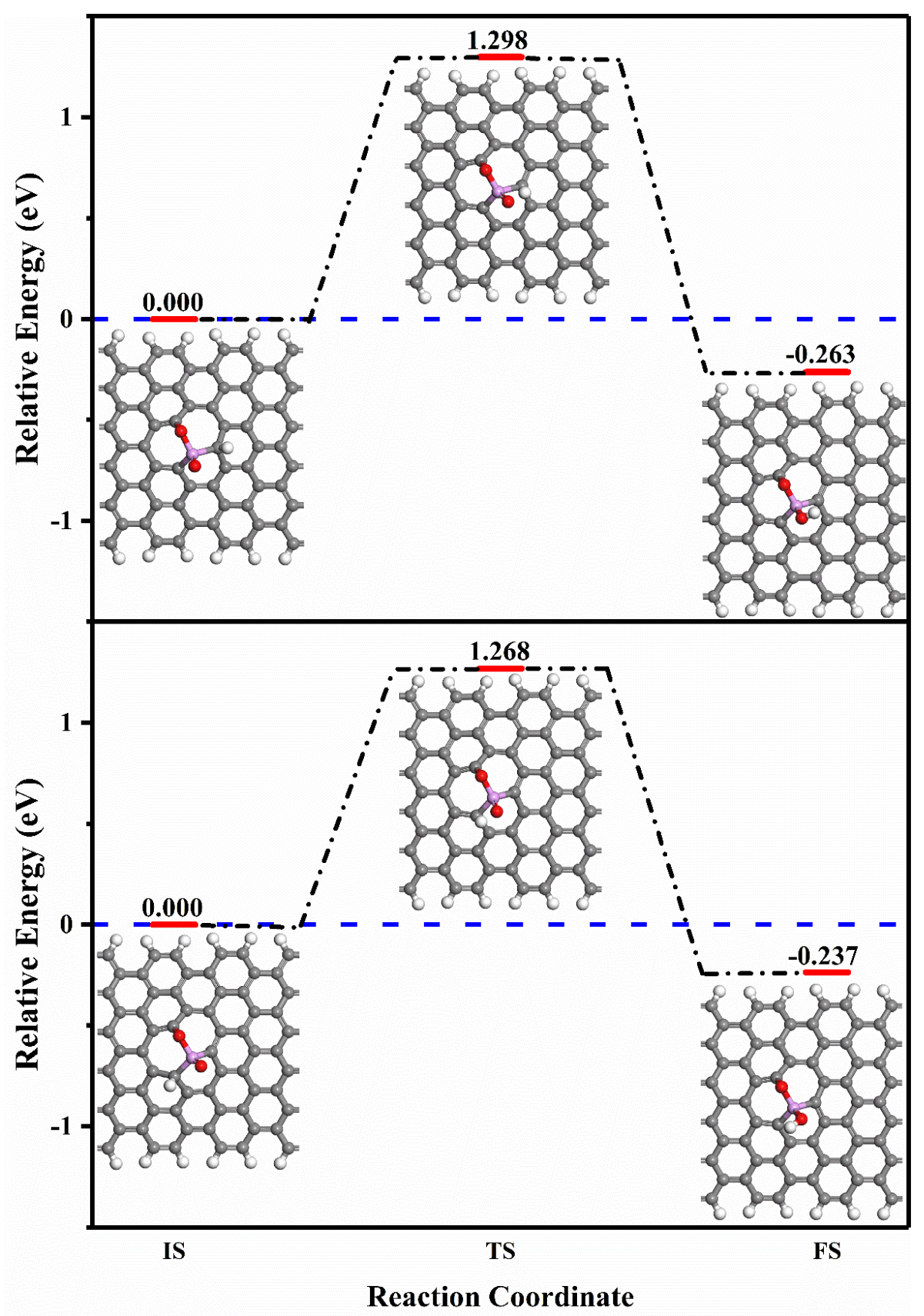

Figure S22: Structures of the initial state (left panel), transition state (middle panel), and final state (right panel) for the reaction: ${ }^{*} \mathrm{H}+{ }^{*}\left(\mathrm{O}+{ }^{*} \mathrm{O}\right) \rightarrow{ }^{*}\left(\mathrm{OH}+{ }^{*} \mathrm{O}\right)$. The figure also includes the reaction heat and reaction barrier. 


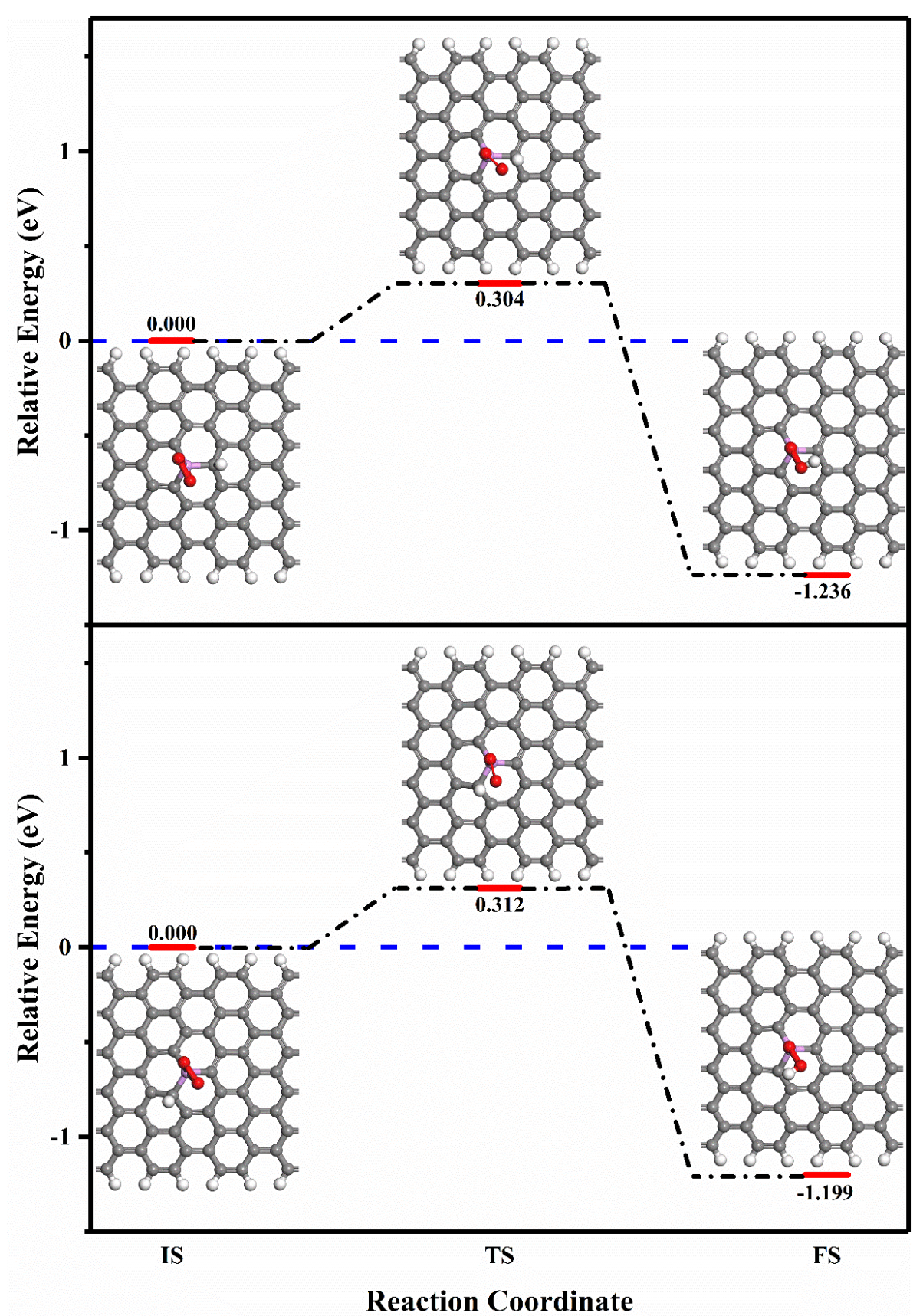

Figure S23: Structures of the initial state (left panel), transition state (middle panel), and final state (right panel) for the reaction: ${ }^{*} \mathrm{O}_{2}+{ }^{*} \mathrm{H} \rightarrow{ }^{*} \mathrm{OOH}$. The figure also includes the reaction heat and reaction barrier. 


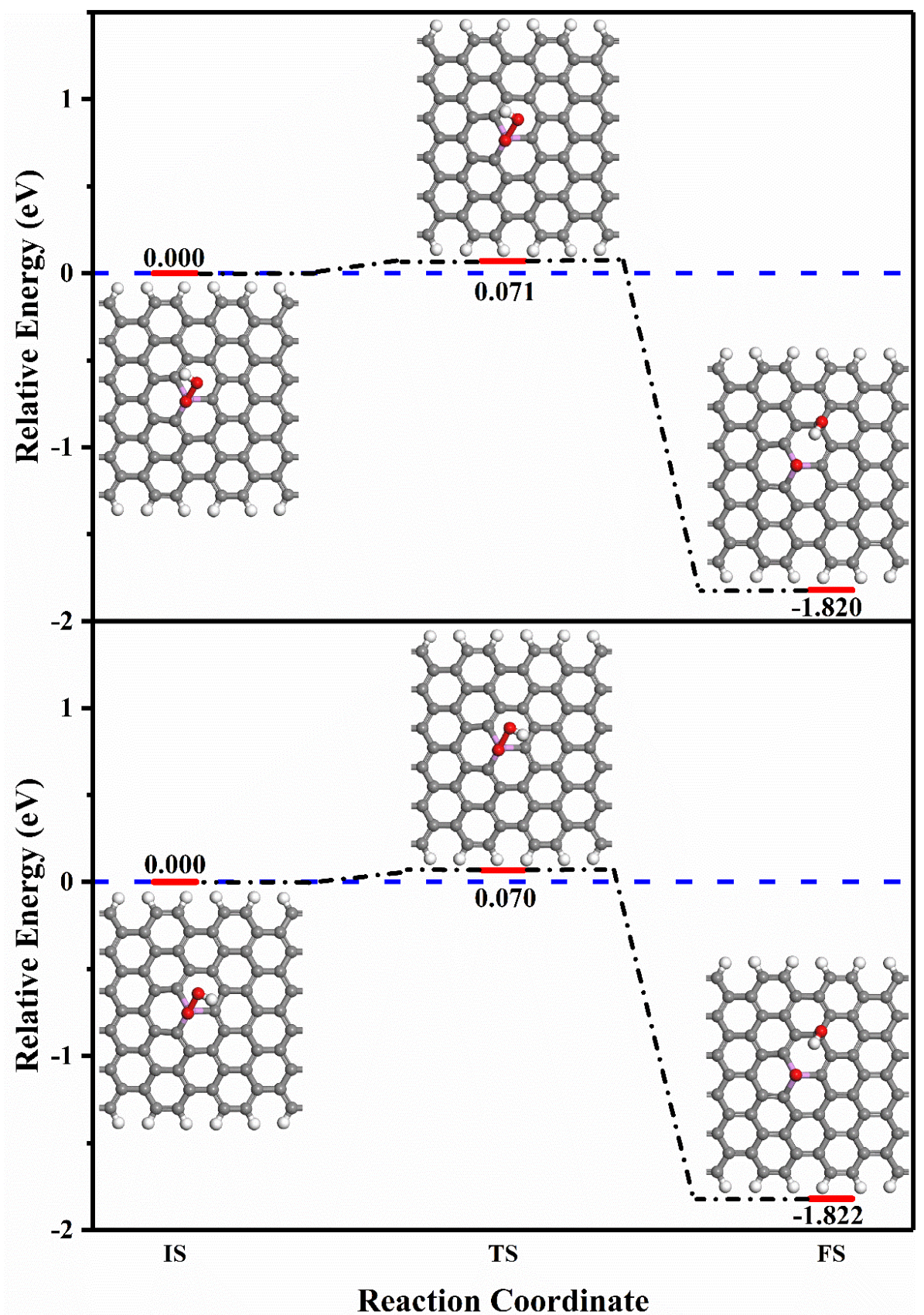

Figure S24: Structures of the initial state (left panel), transition state (middle panel), and final state (right panel) for the reaction: ${ }^{\star} \mathrm{OOH} \rightarrow{ }^{*} \mathrm{OH}+{ }^{*} \mathrm{O}$. The figure also includes the reaction heat and reaction barrier. 


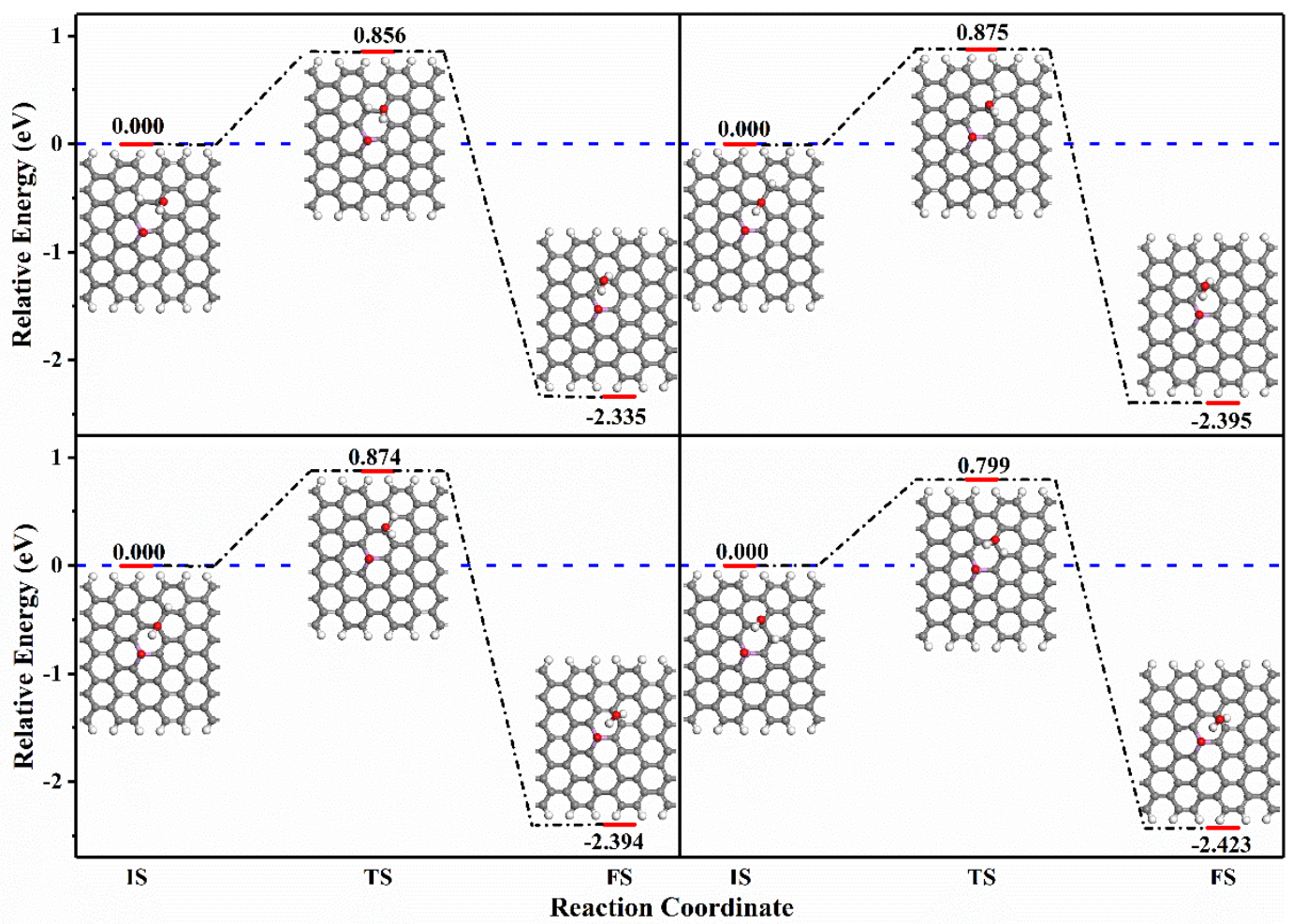

Figure S25: Structures of the initial state (left panel), transition state (middle panel), and final state (right panel) for the reaction: ${ }^{*} \mathrm{OH}+{ }^{*} \mathrm{O}+{ }^{*} \mathrm{H} \rightarrow{ }^{*} \mathrm{O}+\mathrm{H}_{2} \mathrm{O}$. The figure also includes the reaction heat and reaction barrier.

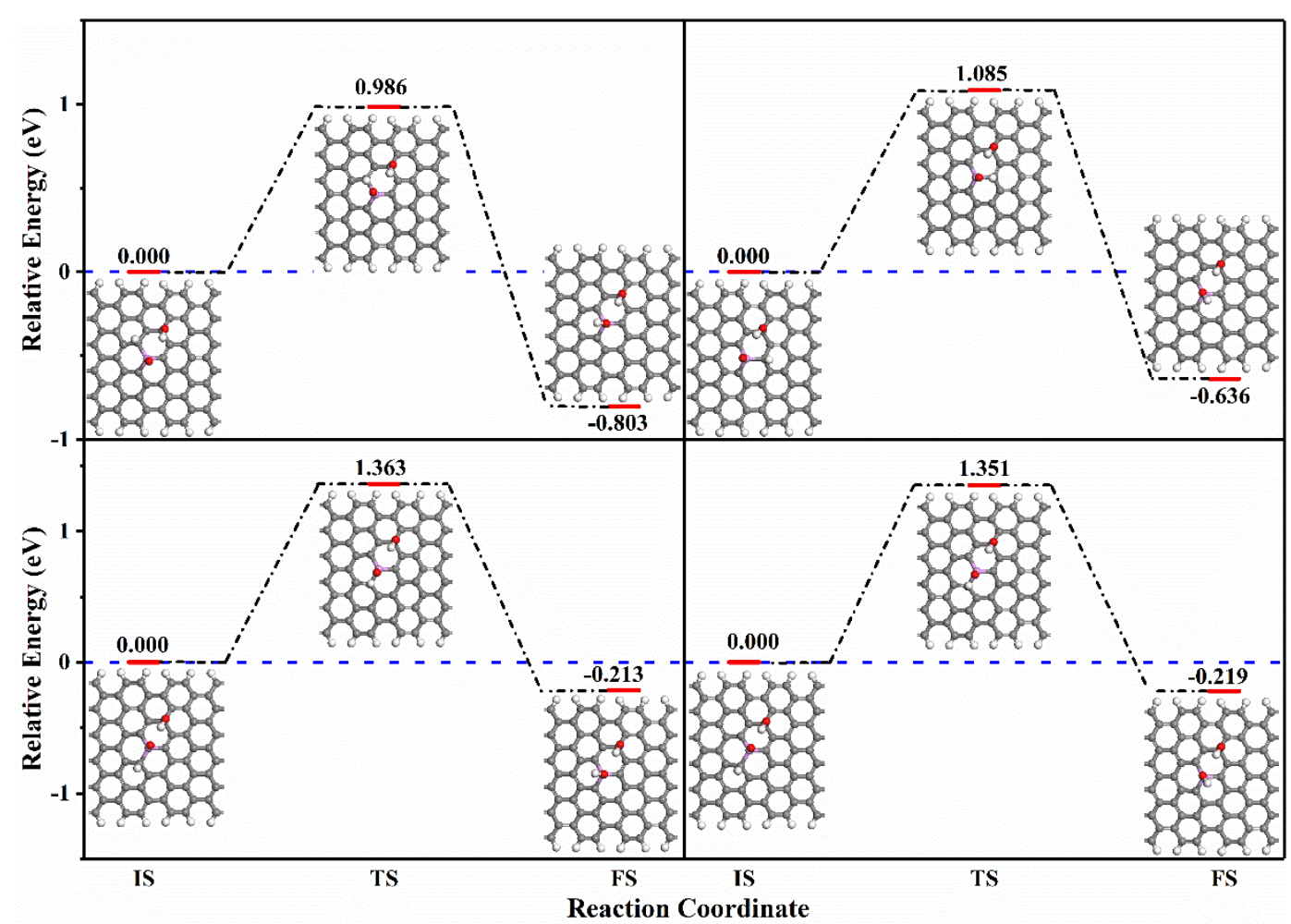

Figure S26: Structures of the initial state (left panel), transition state (middle panel), and final state (right panel) for the reaction: ${ }^{*} \mathrm{OH}+{ }^{*} \mathrm{O}+{ }^{*} \mathrm{H} \rightarrow{ }^{*} \mathrm{OH}+{ }^{*} \mathrm{OH}$. The figure also includes the reaction heat and reaction barrier. 


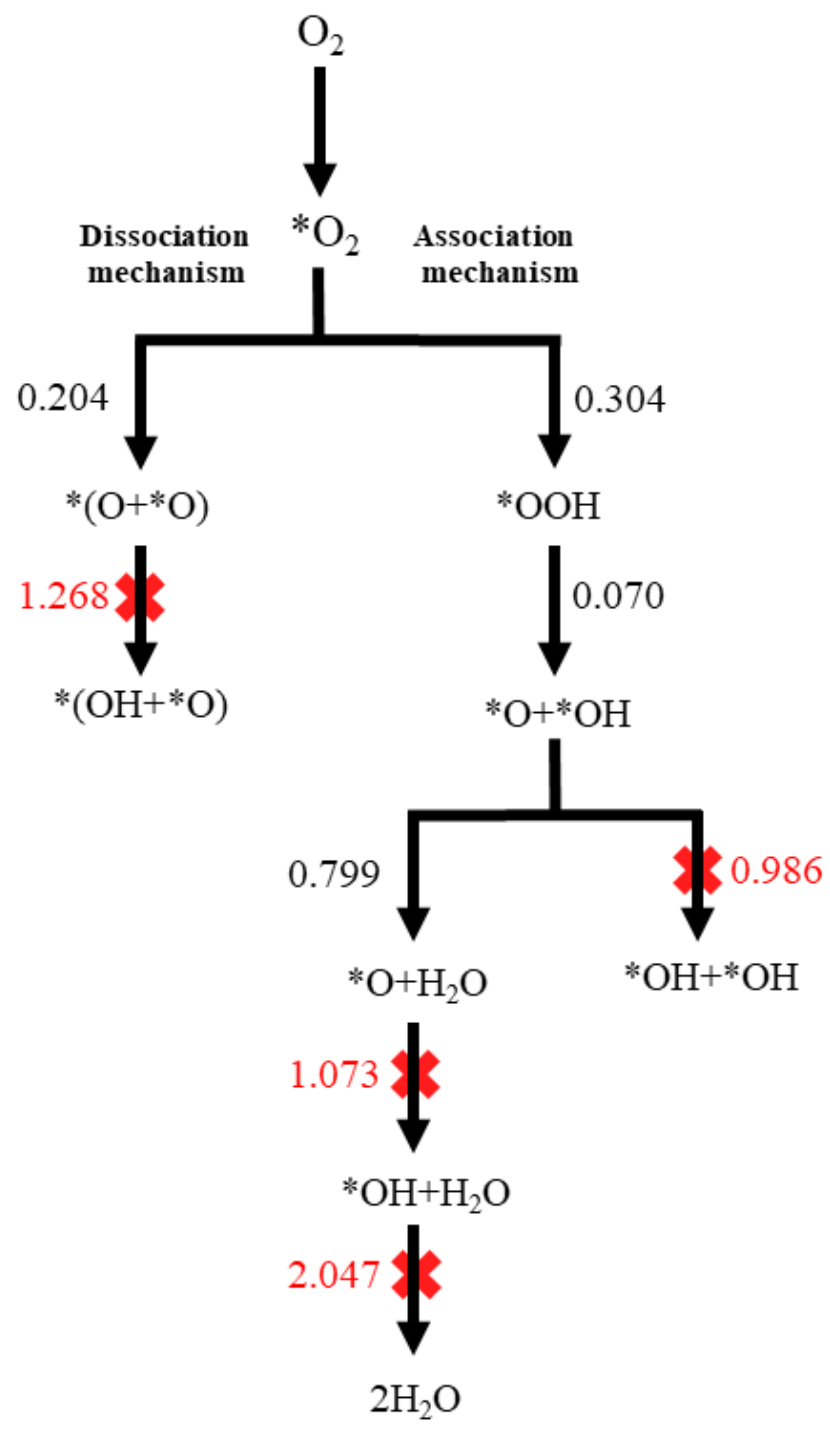

Figure S27: Overall oxygen reduction pathway (ORR) considered here. Black arrow indicates that the reaction is easy, orange arrow indicates that the reaction is difficult, and red arrow indicates that the reaction is very difficult. 